Türkiye Jeoloji Bülteni
Geological Bulletin of Turkey
$61(2018) 51-74$
doi:10.25288/tjb.358177

\title{
Jeolojik, Arkeolojik ve Arkeosismolojik Veriler Işığında Myra Antik Kenti’nde Tarihsel Depremlere Ait Deformasyon Verileri, GB Anadolu
}

Evidence for Historical Earthquake-Related Deformation in the Light of the Geological, Archaeoseismological and Archaeological Data at Ancient City of Myra, SW Anatolia

\section{Mustafa Softa $^{1}$ D, Mehmet Turan² ${ }^{\mathbb{D}}$, Hasan Sözbilir ${ }^{1} \mathbb{D}$}

${ }^{1}$ Dokuz Eylül Üniversitesi, Jeoloji Mühendisliği Bölümü, Tinaztepe Kampüsü, 35390

Buca-İmir, Türkiye

${ }^{2}$ Karadeniz Teknik Üniversitesi, Jeoloji Mühendisliği Bölümü, Kanuni Kampüsü, 61080 Trabzon, Türkiye

Geliş/Received : 10.10.2017 • Düzeltilmiş Metin Geliş/Revised Manuscript Received : 09.11.2017 • Kabul/Accepted : 17.11.2017 • Bask1/Printed : 01.01 .2018 Araștırma Makalesi/Research Article Türkije Jeol. Bül. / Geol. Bull. Turkey

Öz: Batı ve Güneybatı Anadolu'daki eski uygarlıklara ait antik yerleşimlerin birçoğu diri fay zonları üzerinde ve yakın çevresinde kurulmuştur. Güneybatı Anadolu'da, Fethiye-Burdur Fay Zonu ve Pliny-Strabo hendekleri arasındaki bölgede yer alan Myra Antik Kenti de, KD-GB uzanımlı aktif normal fayların üzerinde bulunur. Arkeolojik verilere göre Myra Antik Kenti ve çevresindeki yerleșim alanları tarihsel dönem depremlerinden yoğun olarak etkilenmişlerdir. Antik kentte ve çalışma alanında yapılan detaylı inceleme sonucunda; (i) Tarihsel dönem depremlerinin Myra Antik Kenti'nin neredeyse tamamında izler bıraktığı ve bu izlerin de Holosen zaman dilimi içerisinde gerçekleşmiş M.S. 141, M.S. 240 ve M.S. 344 depremlerinin göstergesi olabileceği (ii) bu depremlerin oluşturduğu deformasyon zonu içindeki antik kentin tiyatro ve liman bölümünde sistematik olarak belirli bir yöne doğru devrilen sütunlar, yıkılmış kolonlar, dönmüş ve eğimlenmiş bloklar şeklinde hasarlar geliştiği (iii) KD-GB uzanımlı bu deformasyon zonunun Kale ve Kekova Faylarının genel gidişi ile uyumlu ve oluşumunun KB-GD yönelimli genişleme ile ilişkili olduğu saptanmıştır.

Anahtar Kelimeler: Arkeosismoloji, Demre, Kale Fayı, Myra Antik Kenti, Tarihsel Deprem

\begin{abstract}
Most of the antique cities in Western and Southwestern Anatolia were established along the active fault zones. The Myra Ancient City, located in the region between the Fethiye-Burdur Fault Zone and the Pliny-Strabo trenches in southwest Anatolia, is situated on the NE-SW trending active normal faults. According to archeological evidence, Ancient City of Myra was affected by historical earthquakes. Analysis of the damaged relics indicates: (i) Nearly all relics of the Myra Ancient City show different degrees of earthquake related damage and these damages may be evidence for 141 A.D., 240 A.D., 344 A.D. earthquakes in the Holocene time interval; (ii) The nekropolis of Myra, amphitheatre and the port of Myra were ruptured as a systematically collapsed columns, collapsed walls, and by rotated and displaced blocks in the damage zone; (iii) NE-SW trending damage zone linked with Kale Fault and Kekova Fault and NW-SE-directed extension is mainly responsible for the recent faulting along the Kale Fault.
\end{abstract}

Keywords: Archaeoseismology, Demre, Historical Earthquakes, Kale Fault, Myra Ancient City

*Yazışma / Correspondence: mustafa.softa@deu.edu.tr

(C) 2018 JMO Her hakkı saklıdır/All rights reserved http://tjb.jmo.org.tr http://dergipark.gov.tr/tjb 


\section{GíRiş}

Antik dönem uygarlıklarının yokoluş nedenleri uzun y1llardan beri incelenen bir konudur. Bugüne kadar antik kentlerde değişik bilim dalları tarafından yapılan çalışmalarda antik dönem uygarlıklarının yokoluş nedenleri; savaş, hastalık, deprem, iklim değişikliği vb. gibidir. Bunların başında yer alan deprem felaketi hem can hem de mal kaybına neden olduğundan antik dönem yapılarında kalıcı izler bırakmış olmalıdır. Arkeolojik yapılardaki sismik kayıtların incelenmesi temeline dayalı olan arkeosismoloji Türkiye'de çok yenidir. Ülkemizde yeni başlayan jeoarkeolojik ve arkeosismolojik çalışmalar birçok araştırmacı tarafından eski uygarlıkların bulunduğu bölgelerin depremselliğinin ve aktif olabilecek fayların ortaya çıkarılmaları konularında çalışılmış ve başarı sağlanmıştır. (Altunel, 1998; Akyüz ve Altunel, 2001; Karabacak, 2011; Karabacak, 2016). Özellikle Batı Anadolu'daki antik yerleşimlerin önemli bir bölümü diri fay zonları üzerinde bulunmasindan dolayı bu fay zonlarının yıkıcı bir deprem üretmesi durumunda, eski uygarlıkların yok olması kaçınılmaz bir sonuç olarak karşımıza çıkmaktadır.

Deprem sismisitesi açısından dünyanın en aktif bölgelerinden biri olan GB Anadolu'da (Rotsein ve Kafka, 1982; Jackson ve McKenzie, 1984; Barka ve Reilinger, 1997) ve özelllikle Demre ve yakın çevresinde diri faylar tanımlanmıştır (Emre vd. 2012). Geniş ölçekte bakıldığında batıda Fethiye-Burdur Fay Zonu ve güneyde Pliny-Strabo hendekleri arasındaki bölgede kalan Demre, KDGB uzanımlı fayların denetlediği yarım graben olarak karada güneye eğimli normal fay olan Kale ve kuzeye eğimli Kekova Fayının ve denizde ise kuzeye eğimli verev atımlı ters fayların denetlediği bir havza konumundadır (Şekil 1a ve 1b). Tarihsel ve aletsel dönemde yoğun sismik aktivite görülen bölgede, günümüzde büyüklüğü 7'ye kadar ulaşan depremler çoğunlukla Fethiye-Burdur Fay Zonu, Pliny-Strabo hendekleri, Kale ve Kekova Faylarını takip etmektedir (Şekil 2a). Tarihsel dönem depremleri ise aktif havza sınırına kurulan Myra ve Andriake gibi birçok antik yerleşimde görüldüğü gibi yoğun tahribatlara sebep olmuştur (Şekil 2b, 2c ve 2d).

Bununla birlikte, Demre ve yakın çevresinde, tarihsel dönemlerde yaşanmış depremlere kaynak olabilecek aktif faylara ilişkin jeolojik arkeosismolojik çalışma bulunmamaktadır. Bu çalışma kapsamında; Myra Antik Kenti ve yakın çevresindeki jeolojik bulgu ve gözlemler ile arkeolojik bulgu ve gözlemler birleştirilerek, antik kentintarihseldönemdegeçirmişolduğudepremlere kaynak olabilecek aktif fayların ve kinematik özelliklerinin belirlenmesi hedeflenmiştir. Demre Ovası'nda yer alan ve Myra Antik Kenti ile yakın çevresini kapsayan bölgenin aktif tektoniğine ilişkin jeolojik inceleme, geçmişte antik kent üzerinde etkili olmuş ve gelecekte de bölgeyi tekrar etkileyebilecek nitelikteki fayların ortaya çıkarılması ve Myra Antik Kenti'ndeki yıkıntı izlerinin bölgede yaşanmış tarihsel depremlerle olan ilişkilerinin belirlenmesi çalışmanın temel amacını oluşturmaktadır. Bu amaç doğrultusunda, Myra Antik Kenti'nde meydana gelmiş olan kırık, çatlak ve diğer hasarlardan yararlanarak antik kentin ve yakın çevresinin arkeosismolojik açıdan incelenmesi ve ayrica antik kentin tarihi bilgisi ile elde edilen gözlem ve verilerin sentezlenerek aktif tektonik, arkeoloji, uzaktan algılama gibi disiplinlerin metodolojilerinden kentin geçirmiş olduğu depremler ve bunların kentteki izleri yorumlanmıştır. 

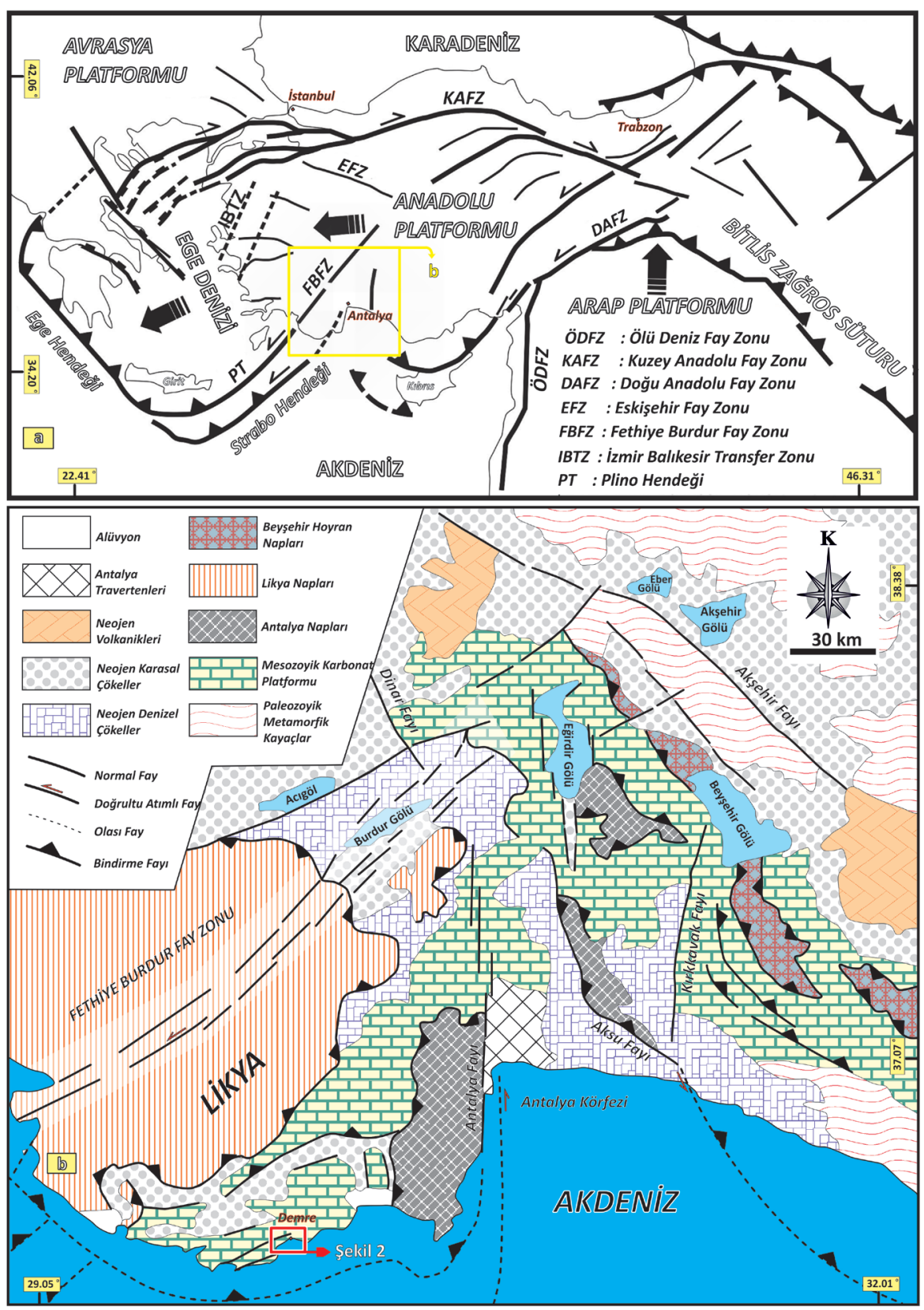

Şekil 1 a: Anadolu ve Akdeniz bölgesinin ana tektonik yapıları. Şekildeki siyah kalın oklar plakaların hareket yönlerini göstermektedir (Gürer vd. (2004); Eyüboğlu vd. (2013) ve Sözbilir vd. (2011)'den basitleştirilerek). b: Güneybatı Türkiye'nin jeoloji haritası (MTA tarafından yayınlanan 1/500,000 ölçekli jeoloji haritasından değiştirilerek), (Şenel (1997), Konak ve Şenel (2002), Gürer vd. (2004), Bozcu vd. (2007) ve Hall vd. (2009) birleştirilerek).

Figure 1 a: Main tectonic elements of Anatolia and the Mediterranean region. Black bold arrows show directions of plate motion relative to Eurasia and simlified from Gürer at al. (2004); Eyüboğlu et al. (2014) and Sözbilir et al. (2011). b: Geological map of Southwestern Turkey modified after 1/500,000-scale geological map sheets published by Mineral Research and Exploration Directorate of Turkey; Şenel (1997) and Konak and Şenel (2002), combine with Gürer et al. (2004), Bozcu et al. (2007), Hall et al. (2009). 


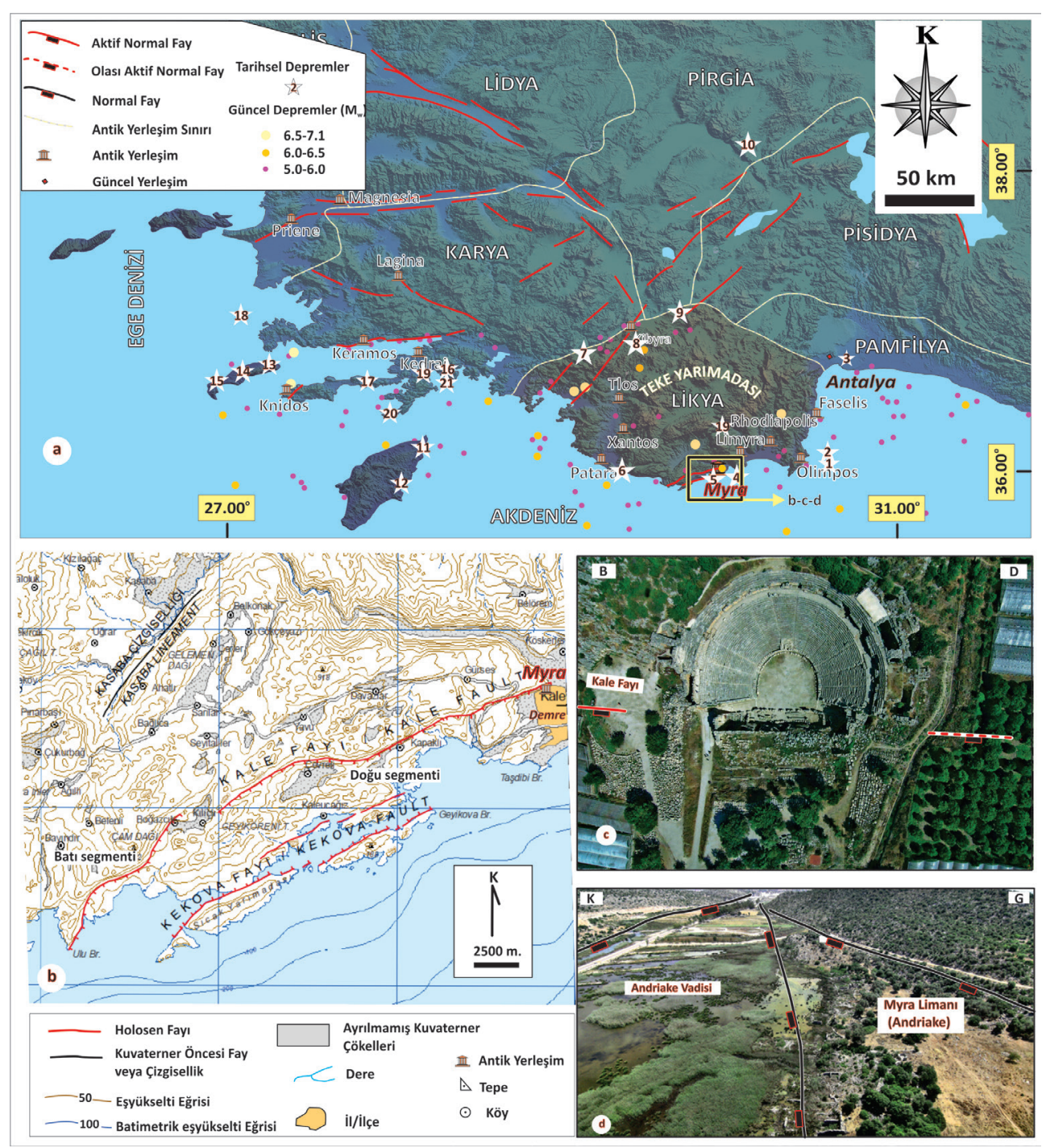

Şekil 2 a: Güney Batı Anadolu'daki Roma dönemindeki Antik yerleşimlerin sınırları ve Myra antik kenti ve yakın çevresinde görülen diri fayların, Aletsel ve Tarihsel depremlerin dağılımı (Deprem verileri, Kandilli Rasathanesi ve Deprem Araştırma Enst., Soysal vd. (1981); Guidoboni vd. (1994); Ambraseys ve Finkel (1995); Kondorskaya ve Ulumov (1999); Bayburtluoğlu (2003); Duggan (2005); Erel ve Adatepe (2007); Altınok vd. (2011)'den birleştirilerek). b: Kale Fayı'na ait segmentlerin diri fay haritasında görünümü (Emre vd. (2012)). c: Kale Fayı'nın Myra Antik Kenti'nin tiyatrosundaki izinin hava fotoğrafinda görünümü. d: Andriake liman koyunu denetleyen Kekova Fayının uzanımının ve Andriake' nin hava fotografinda görünümü.

Figure 2 a: Ancient regions border of the Roman period in western Anatolia and major active fault, major ancient settlements of the Myra region and historical earthquakes historical and instrumental seismic events in Turkey and surrounding areas (earthquakes produced from Kandilli Observatory and Earthquake Research Institute, http: koeri.boun.edu.tr and combined with Soysal et al. (1981); Guidoboni et al. (1994); Ambraseys \& Finkel (1995); Kondorskaya \& Ulumov (1999); Bayburtluoğlu (2003); Duggan (2005); Erel \& Adatepe (2007); Altınok et al. (2011). b: The view of the segment of Kale Fault in map of active fault of Turkey (Emre et al. (2012)). c: The view of Kale Fault on the aerial photos in Ancient city of the Myra theater. d: The aerial photo shows port of Myra (Andriake) and Andriake which are controlled by Kekova Fault. 


\section{YÖNTEM}

Çalışılan alanda 2010-2012 ve 2017 yılları arasında gerçekleştirilen arazi çalışmalarıyla elde edilen veriler büro çalışmaları ile yorumlanmıştır. Arazi çalışmaları, jeolojik ve arkeosismolojik incelemeler olmak üzere iki başlık altında toplanmıştır. Jeolojik çalışmalar sırasında $1 / 25000$ ölçekli jeoloji haritası yapılmış ve bölgede gözlenen diri faylar harita üzerine işlenmiştir. Arkeosismolojik incelemeler kapsaminda, bölgeyi etkileyen tarihsel depremlerin Myra Antik Kenti'ndeki izleri detaylı olarak incelenmiştir. Laboratuvar çalışmaları kapsamında ise, 30 metre çözünürlüklü SRTM verileriyle ArcGIS 10.2.2 programında detaylı çalışılarak bölgenin 3 boyutlu modeli oluşturulmuş ve araziden toplanan kinematik verilerle Faultkinwin-7 program1 üzerinde Kale Fayına ait Paleostress analizleri değerlendirilmiştir.

\section{BÖLGENIN JEOLOJIK-NEOTEKTONIK ÖZELLIIKLERİ VE DEPREMSELLİĞİ}

Demre ve çevresindeki temel kayalarını Beydağları Otoktonu'na ait Jura-Kretase yaşlı platform tipi kireçtaşlarından oluşan Beydağları Formasyonu'nun karbonatları oluşturur (Günay vd., 1982; Dumont ve Kerey, 1975; Poisson, 1977; Koçyiğit, 1981 ve 1983; Ersoy, 1990), (Şekil 3). Demre ovasını kuzeyden güneye doğru kateden büyük debili Demre Çayı'nın taşıdığı Kuvaterner yaşlı alüvyon birimleri ise Üst Kretase yaşlı Beydağları formasyonunun platform karbonat birimlerini uyumsuz olarak üzerlemektedir.

İnceleme alanı ve yakın çevresinin tarihsel ve aletsel dönemde yoğun bir sismik etkinliğe sahip olduğu görülmektedir. Bölgede gözlenen M.S. 60-1900 yılları arasındaki depremleri harita üzerinde incelediğimizde depremlerin denizaltı morfolojisi, Fethiye Burdur Fay Zonu, Kale Fayı ve Kekova Fayı'nın olduğu bölgede yoğunlaştı̆̆1 izlenmektedir (Şekil 2a). Aynı zamanda Fethiye Burdur Fay zonu üzerinde bulunan Kibyra Antik Kenti de Myra Antik Kenti gibi bu fay zonunun ürettiği depremlerden ve bölgedeki yoğun depremlerden oldukça şiddetli şekilde etkilenmiştir. Emre ve diğ. (2012) çalışmasında bu zon, diri fay olarak tanımlanmış ve bu fay zonu boyunca yapılan jeolojik çalışmalar fayın yıkıcı deprem üretebileceğini ve GPS çalışmaları ile halen aktivitesini sürdürdügüunü göstermiştir (Barka ve Reilinger, 1997; Taymaz ve Price, 1992; Akyüz ve Altunel, 2001; Karabacak, 2011).

Myra Antik Kenti'nin de içinde yer aldığı Demre ilçesi, Türkiye Deprem Bölgeleri Haritası'nda sismik etkinliğin yoğun olduğu 1 . Derece Deprem bölgesi içerisinde yer almaktadır. $\mathrm{Bu}$ bölgede son yüzy1lda büyüklüğü $\left(\mathrm{M}_{\mathrm{w}}\right)$ 5-7.1 arasında değişen oldukça yoğun depremsellik görülmektedir (Şekil 2a). Tarihsel dönem deprem kayıtlarına bakıldığında Myra Antik Kenti'nin de içinde bulunduğu tüm Likya kıyıları önemli derecede hasar görmüştür (Çizelge 1).

Bean (1978) ve Duggan (2004)'nın çalışmalarına göre M.S. 13-37'deki yıkıcı depremden sonra Patara Antik Kenti'ndeki tiyatro bolümü yoğun hasar görmüştür. Fethiye Burdur Fay Zonu üzerinde M.S. 23 yılındaki depremden Kibyra Antik Kenti ağır şekilde etkilenmiştir (Bean, 1978; Duggan, 2004; Karabacak vd., 2013). Likya kıyılarının büyük bir bölümünde özellikle Myra Antik Kenti'ne yoğun hasar veren M.S. 60-68 depreminin ardından Myra ve Patara'da tsunami meydana gelmiştir (Guidoboni vd., 1994; Öner, 1998). MS 141'de Rodos, Likya ve Karya'da ciddi zararlar yaratan 7 büyüklügündeki depremden Myra, Trebendai, Sura, Ision antik kentleri de etkilenmiştir. $\mathrm{Bu}$ depremden sonra buralarda ve daha birçok yerde (Xanthos, Olympos, Pinara, Tlos, Letoon, Choma, Podalia, Arycanda, Oinoanda, Calynda, Cyaneae, Aperlae, Nysa, Sidyma, Acalissos, Patara, Perge, Termessos) hayırsever Opramoas tarafından taş tiyatrolar, hamam, tapınak vb. yapılar onarılarak restore edilmiştir (Bayburtluoğlu, 2003; Bean, 1978; Duggan, 2004). Bayburtluoğlu (2003 ve 2004) çalışmasında M.S. 240 ve M.S. 385 yıllarında Arycanda merkezli neredeyse tüm Likya kıyı şeridi boyunca hasara neden olan depremler meydana geldiğini ifade etmiştir. 


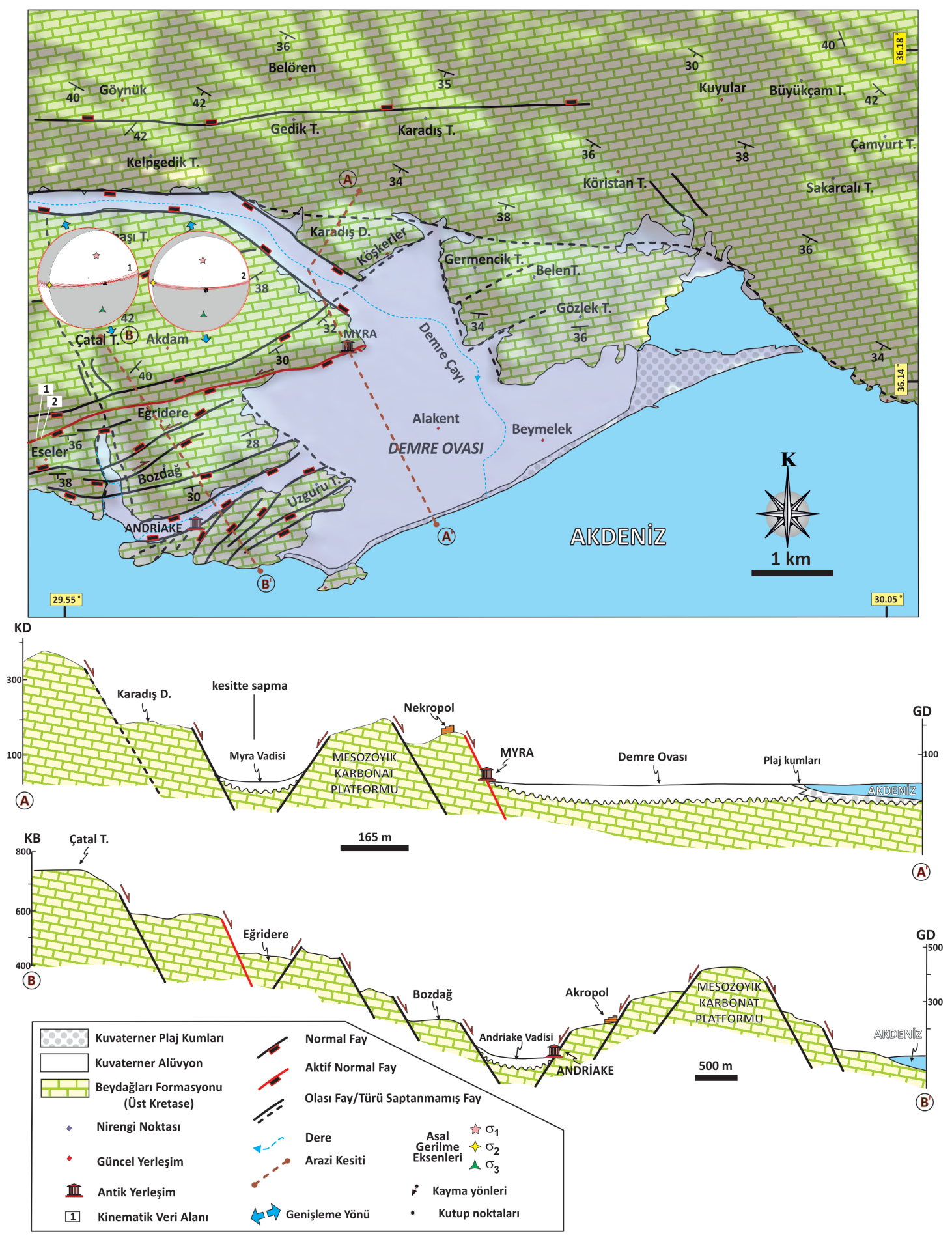

Şekil 3: Demre ve yakın çevresinin 1/25000 ölçekli jeoloji haritası ve Arazi tabanlı jeolojik kesitler, genç havza dolgularının ve daha yaşlı temel kayalarının yapısal ve stratigrafik ilişkilerini göstermektedir.

Figure 3: 1/25000 scale detailed geological map of Demre and surrounding regions and Field-based geologic crosssections showing stratigraphic and structural relationships of basin fill units with older basement units. 
Çizelge 1. GB Anadolu ve yakın çevresinde hissedilen tarihsel dönem depremlerinin dağılımı (Soysal vd. (1981 ; Guidoboni vd. (1994) $)^{\mathrm{a}}$; Ambraseys ve Finkel (1995) ${ }^{\mathrm{g}}$; Kondorskaya ve Ulumov (1999) ${ }^{\mathrm{b}}$; Bayburtluoğlu (2003) Duggan (2004) $)^{\mathrm{c}}$; Erel ve Adatepe (2007) ; Altınok vd. (2011) ${ }^{\mathrm{e}}$ 'den birleştirilerek).

Table 1. Historical earthquakes and their magnitudes in coast of SW Anatolia and surrounding area (Combined with Soysal et al. (1981) ; Guidoboni et al. (1994) ; Ambraseys \& Finkel (1995)g; Kondorskaya \& Ulumov (1999) ; Bayburtluoğlu (2003); Duggan (2004)c; Erel \& Adatepe (2007)d; Altınok et al. (2011) .

\begin{tabular}{|c|c|c|c|c|}
\hline Numara & Zaman & Lokasyon & Şiddet & Açıklamalar \\
\hline $1^{\mathrm{a}}$ & 88-MÖ & $38.0781-30.1609$ & $?$ & \\
\hline $2^{b}$ & 60-MS & $37.8000-29.1000$ & IX & \\
\hline $3^{\mathrm{a}}$ & 68-MS & Likya Kıyıları ve Demre & IX & Tsunami \\
\hline $4^{\text {acde }}$ & 141/142-MS & Myra-Demre & VIII & \\
\hline $5^{\mathrm{d}}$ & 144-MS & Fethiye-Kalkan & VIII & \\
\hline $6^{\mathrm{f}}$ & 240-MS & Myra-Arycanda & $?$ & \\
\hline $7^{\mathrm{d}}$ & 344-MS & Rhodos & IX & \\
\hline $8^{\mathrm{a}}$ & 494-MS & $37.8383-29.0866$ & IX & \\
\hline $9^{\mathrm{ac}}$ & 529/530-MS & Myra & VIII & \\
\hline $10^{\mathrm{g}}$ & 1609-MS & Rhodos & IX & Tsunami \\
\hline $11^{\mathrm{g}}$ & 1741-MS & Rhodos & VIII & Tsunami \\
\hline $12^{\mathrm{c}}$ & 1743-MS & Antalya & $?$ & Tsunami \\
\hline $13^{\mathrm{g}}$ & 1756-MS & Doğu Akdeniz & $\mathrm{V}$ & \\
\hline $14^{\mathrm{h}}$ & 1759-MS & Akdeniz Kıyıları & VIII & \\
\hline $15^{\mathrm{h}}$ & 1849-MS & Akdeniz Kıyıları & VI & \\
\hline $16^{\mathrm{h}}$ & 1857-MS & $36.800-28.300$ & VI & \\
\hline $17^{\mathrm{h}}$ & 1869-MS & $36.800-27.900$ & VIII & \\
\hline $18^{\mathrm{h}}$ & 1885-MS & $37.800-28.200$ & IX & \\
\hline $19^{\mathrm{h}}$ & 1887-MS & Akdeniz Kıyıları & VII & \\
\hline $20^{\mathrm{h}}$ & 1896-MS & $36.5000-28.000$ & $\mathrm{X}$ & \\
\hline $21^{\mathrm{h}}$ & 1897-MS & $36.8000-28.3000$ & VI & \\
\hline
\end{tabular}


Guidoboni vd. (1994); Ötüken (1996) ve Duggan (2004) Myra-Demre'ye yoğun hasar veren diğer bir depremin M.S. 529-530 depremi olduğunu ve bu sarsintıdan kırık hattı boyunca oluşan yatay yer değiştirmenin Kekova yakınlarında 7 metreye eriştiğini saptamışlardır. Aynı zamanda bu depremden tüm Likya kıyıları ağır bir şekilde etkilenmiş ve bu olay M.S. 68 yılında Likya sahillerindeki Myra, Patara, Xanthos, vb. gibi aynı alanları etkileyen depremin ve tsunaminin tekrar ettiğini göstermektedir (Çizelge 2). 7. yüzyılda Myra'da iki büyük sarsıntı meydana gelmiş ve Aparlea, Kekova ve Simena'nın denizin içine batarak Antalya'nın batık kentlerinin şekillenmesine neden olmuştur (Verstraten ve diğ., 2000; Duggan, 2004).

1489, 1492 ve 1741 y1llarında Rodos ve yakın çevresini etkileyen depremler meydana gelmiştir. $\mathrm{Bu}$ depremler deniz içinden geçen tektonik hatlarda meydana gelmiş ve sonrasında tüm Likya kıyılarını etkileyen tsunamiler oluşmuştur (Soysal vd., 1981; Ambraseys ve Finkel, 1995; Duggan, 2004). 1743, 1759, 1849, 1858, 1887 ve 1911 'de depremler Antalya ve Rodos kıyılarını etkilemiştir (Soysal vd., 1981; Ambraseys ve Finkel, 1995; Özhan, 2004; Duggan, 2004; 2005). 1969 ve 1975 yıllarındaki depremlerde tüm Akdeniz kıyıları, özellikle Kaş,

Kalkan, Rodos ve yakın çevresi etkilenmiştir (Ayhan vd, 1983; Duggan, 2004; Demirtaş, 2005; Duggan, 2005). Fakat yukarıda açıklanan tarihsel deprem kayitlarında, Myra Antik Kenti'ndeki yapılarla ilgili hasar kayıtları bulunmamaktadır.

\section{Kale Fayı}

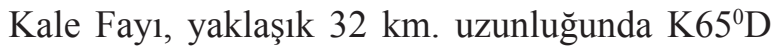
uzanımında morfolojik olarak iç bükey yapı sunan iki parçalı verev atımlı normal bir faydır. Kale
Fayı'nın doğu segmenti, arazide Kale Mevkii'nden başlayıp Kapaklı Mevkii istikametinde ilerlemektedir. Batı segmenti ise Boğazcık Mevkii'nden başlayıp deniz içerisine Stroggili adası güneybatısı boyunca devam eder (Emre vd. 2012). Bu iki segment, Boğazcık mevkiinde birbirlerine aktarım rampası ile bağlanmaktadır (Şekil 2b).

Kale Fayı'nın doğu segmenti Kale yakınlarında alüvyon ile Mesozoyik karbonat platformu kireçtaşlarının sınırını oluşturur. (Şekil 3). Çalışma alanında bu kireçtaşları içerisinde çok net gözlenen kırık hattı, uzanımındaki ötelenmeler, ani topoğrafya değişimi, içerisinden geçtiği antik kentin tiyatro ve birçok kesimlerine verdiği hasarlar göz önüne alınarak harita üzerine konumlandırılmıştır.

Kale Fayı'nın doğu segmenti, inceleme alanında Eseler Mahallesi'nden başlar ve Myra Antik Kenti'nin tiyatrosundan geçerek, Belen Tepe istikametine devam eder. Çalışma alanı içerisinde yaklaşık $5 \mathrm{~km}$. izlenebilmektedir (Şekil 4a). Kale Fayı üzerinde gözlenebilen iki istasyonda kinematik/yapısal ölçümler yapılmıştır. İki istasyondaki $75^{\circ}-82^{\circ}$ arasında değişen eğime sahip yükssek açılı fay düzlemleri üzerinde yapısal ögeler saptanmıştır (Şekil 4b ve 4d). Fay düzlemi üzerinde yapılan incelemelerde kayma çizikleri tespit edilmiş olup, bunlar $64-70^{\circ} \mathrm{D}$ ve $78-85^{\circ}$ D dır (Şekil 4c, 4e ve Çizelge 4). 1. istasyondan alınan ölçüler, fayın oluşumundan sorumlu asal gerilme konumlarının en büyükten en küçüğe $(\sigma 1-\sigma 3)$ doğru sirasiyla 38,0/50,9, 264,8/22,1 ve $162,1 / 30,3$ ve 2 . istasyondan alınan ölçüler sirasiyla $11,4 / 55,7,268,0 / 9,0$ ve $172,1 / 32,8$ olduğunu göstermektedir. Toplanan veriler değerlendirildiğinde fayı oluşturan paleostress yönleri açılma ile ilişkili ve iki lokasyonda da yaklaşık KB - GD uzanımlıdır (Şekil 3). 
Çizelge 2. Myra Antik Kenti'ndeki ana yapıların onarımları ve depremlerle olan ilişkileri.

Table 2. A review of reconstruction of major buildings and its related with historical earthquakes at Myra.

\begin{tabular}{|c|c|c|c|c|}
\hline Zaman & & Açıklamalar & Depremler & Kaynaklar \\
\hline 800 & & Kentin terkedilmesi & & $\begin{array}{c}\text { Tekinalp, 2000; } \\
\text { Çevik ve Bulut, } 2010\end{array}$ \\
\hline 700 & \multirow{7}{*}{ 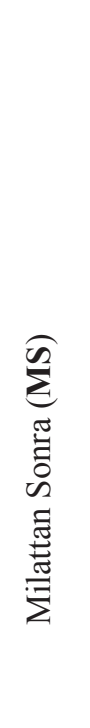 } & Depremler bölgede şiddetli olarak hissedilmiş & M.S. 7. yy. & $\begin{array}{c}\text { Guidoboni vd., 1994; } \\
\text { Duggan, } 2005\end{array}$ \\
\hline \multicolumn{5}{|l|}{600} \\
\hline 】 & & Depremler bölgede şiddetli olarak hissedilmiş & M.S. 529-530 & $\begin{array}{l}\text { Guidoboni vd., 1994; } \\
\text { Duggan, } 2004\end{array}$ \\
\hline 500 & & \multirow{3}{*}{$\begin{array}{l}\text { Depremlerin neden olduğu sarsintılar sonucunda } \\
\text { Limanda ve kentin tiyatrosunda restorasyonlar }\end{array}$} & \multirow{4}{*}{ M.S. 344} & \multirow[b]{3}{*}{$\begin{array}{l}\text { Gu1doboni vd., 1994; } \\
\text { Duggan, } 2004\end{array}$} \\
\hline 400 & & & & \\
\hline $\mathbf{I}$ & & & & \\
\hline 300 & & Depremlerin neden olduğu sarsintılar sonucunda & & Çevik ve Bulut, 2010 \\
\hline 】 & & $\begin{array}{c}\text { Limanda ve kentin Agorasında büyük çaplı } \\
\text { restorasyonlar }\end{array}$ & M.S. 240 & \\
\hline \multicolumn{5}{|l|}{200} \\
\hline ! & & $\begin{array}{l}\text { Depremlerin neden olduğu sarsintılar sonucunda } \\
\text { Tiyatronun büyük bölümünde restorasyon }\end{array}$ & M.S. 141 & $\begin{array}{l}\text { Coulton, 1978; Arca, } \\
\text { 2002; Çevik, 2010a- } \\
\text { b }\end{array}$ \\
\hline \multicolumn{5}{|l|}{100} \\
\hline ! & & $\begin{array}{c}\text { Depremler bölgede şiddetli olarak hissedilmiş ve } \\
\text { Tsunamiden etkilenmiş }\end{array}$ & M.S. $60-68$ & $\begin{array}{l}\text { Guidoboni vd., 1994; } \\
\text { Kondorskaya ve } \\
\text { Ulumov, } 1999\end{array}$ \\
\hline \multicolumn{5}{|l|}{$\mathbf{0}$} \\
\hline 100 & & & & \\
\hline 200 & $\stackrel{0}{\Sigma}$ & & & \\
\hline \multicolumn{5}{|l|}{300} \\
\hline $400 / 500$ & & Myra Antik Kenti'nin kuruluşu & & $\begin{array}{l}\text { Babelon, 1907; Kolb } \\
\text { ve Tietz, } 2001\end{array}$ \\
\hline
\end{tabular}



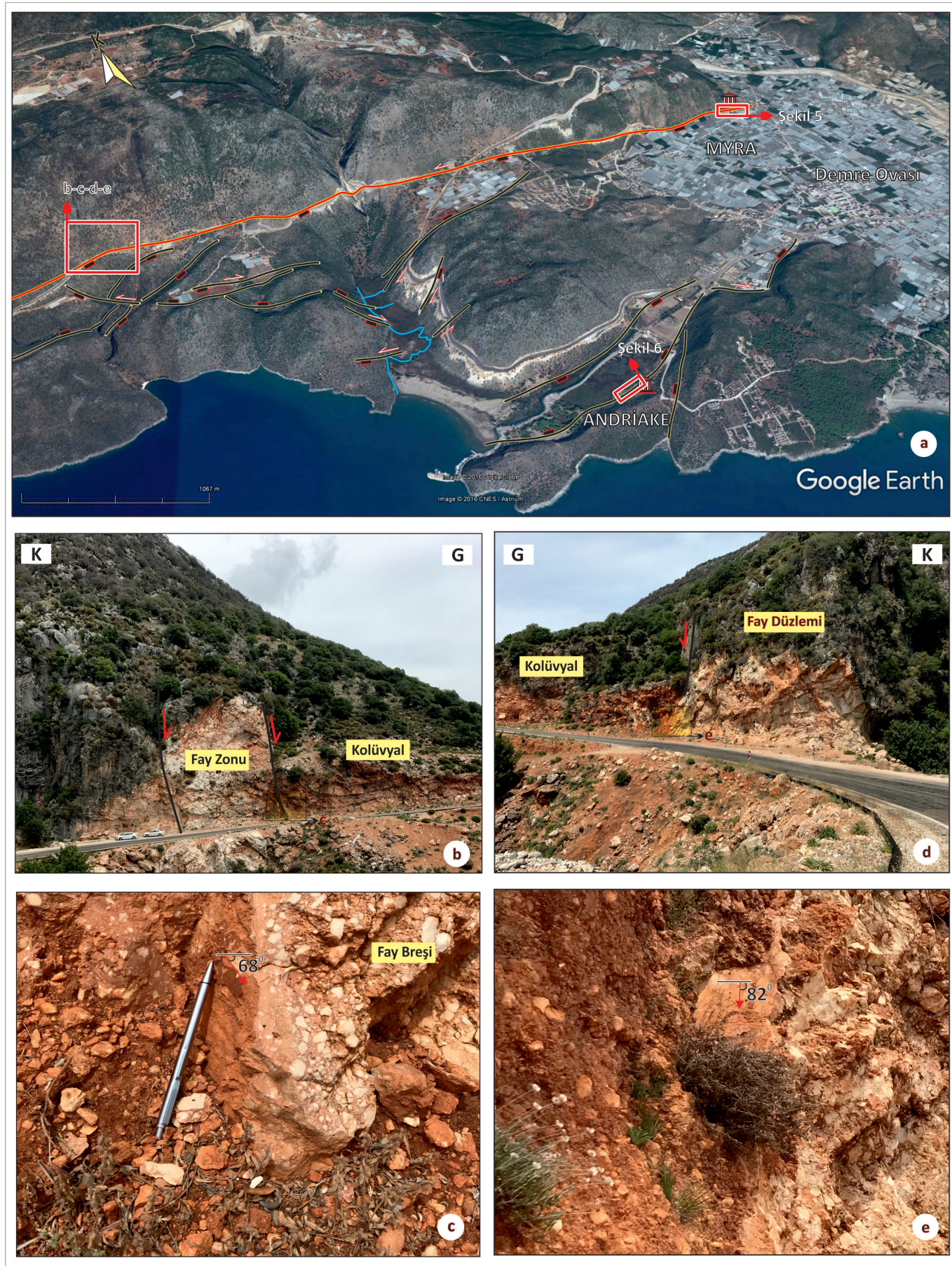

Şekil 4 a: Myra antik kentini etkileyen diri fayın ve potansiyel aktif olabilecek fayların uydu görüntüsü. b-d: Eseler mahallesinin kuzeyindeki yol yarmasında kireçtaşları üzerinde Kale Fayı'nın düzlemlerinin görünümü. c-e: Kale Fayının kireçtaşları üzerindeki kayma çiziklerinin görünümü.

Figure 4 a: Satellite photo of active faults and potentially active faults that effected the ancient city of Myra. $b$-d: The appearance of the fault planes of the Kale Fault on the limestones along the road of Eseler. c-e: The view of the slickensides on the limestone of the Kale Fault. 
Çizelge 4. Kale Fayına ait iki farklı lokasyonda toplanan kinematik verilere ait değerler.

Table 4. The kinematic datas collected at two different locations of the Kale Fault.

\begin{tabular}{|c|c|c|c|c|}
\hline \multirow{13}{*}{ 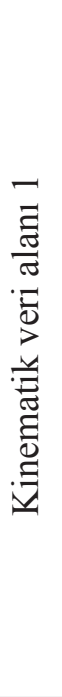 } & Düzlem Sayıs1 & Doğrultu & Eğim & Rake Açıs1 \\
\hline & 1 & K85D & 79GD & 64GD \\
\hline & 2 & K84D & 80GD & $65 \mathrm{GD}$ \\
\hline & 3 & K82D & 78GD & $65 \mathrm{GD}$ \\
\hline & 4 & K80D & $80 \mathrm{GD}$ & 66GD \\
\hline & 5 & K78D & $80 \mathrm{GD}$ & 64GD \\
\hline & 6 & K83D & 79GD & $66 \mathrm{GD}$ \\
\hline & 7 & K81D & $80 \mathrm{GD}$ & 70GD \\
\hline & 8 & K76D & 78GD & $65 \mathrm{GD}$ \\
\hline & 9 & K74D & $80 \mathrm{GD}$ & 67GD \\
\hline & 10 & K70D & 79GD & 64GD \\
\hline & 11 & K85D & $75 \mathrm{GD}$ & 66GD \\
\hline & 12 & K81D & 78GD & $65 \mathrm{GD}$ \\
\hline \multirow{12}{*}{ 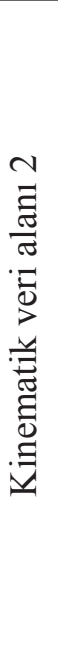 } & 1 & D-B & $79 \mathrm{G}$ & $80 \mathrm{D}$ \\
\hline & 2 & K88B & $80 \mathrm{~GB}$ & 76GD \\
\hline & 3 & K89D & 79GD & 74GD \\
\hline & 4 & K89B & $82 \mathrm{~GB}$ & 78GD \\
\hline & 5 & D-B & $80 \mathrm{G}$ & $75 \mathrm{D}$ \\
\hline & 6 & K89B & $78 \mathrm{~GB}$ & $85 \mathrm{GD}$ \\
\hline & 7 & K88D & 78GD & $76 \mathrm{GD}$ \\
\hline & 8 & D-B & $76 \mathrm{G}$ & $74 \mathrm{D}$ \\
\hline & 9 & D-B & $80 \mathrm{G}$ & $76 \mathrm{D}$ \\
\hline & 10 & K89D & 76GD & 73GD \\
\hline & 11 & D-B & $78 \mathrm{G}$ & $82 \mathrm{D}$ \\
\hline & 12 & K88D & $76 \mathrm{GD}$ & $72 \mathrm{GD}$ \\
\hline
\end{tabular}

İnceleme alanında kırık hatları boyunca Karaçamlık deresinin (36 13 ' 20" K-29 57' 09”, D) yanal yönde yaklaşı1k 240 metre yer değiştirmesi, hat boyunca uzamış sırtların varlığı ve son iki yıl içerisinde 7 Ekim 2015'de Kale yakınlarında meydana gelen $\mathrm{M}_{\mathrm{w}}: 5,2$ büyüklügüündeki depremin odak mekanizmasının verev atımlı normal fay çözümünü vermesi Kale Fayı'nın günümüzde de diriliğini koruduğu düşüncesini desteklemektedir. Kale Fayı'nın güneyinde kalan alanlarda bu faya paralel ve çalışma alanı dışında Kale Fayı'na bağlandığı düşünülen birçok sintetik ve antitetik fay setleri de bulunmaktadır (Şekil 3). Bu fay setlerinin, kademeli yerleşimi, güney bloklarının düşmüş olması, Kale Fayı'na yer yer paralellik arz etmeleri ve bölge jeomorfolojisinin şekillenmesini önemli oranda denetlemiş olmaları gibi veri ve gözlemler, bu fayların bölgenin yapısal geçmişinde önemli rol oynayan ikinci derece potansiyel diri fay olduklarının en iyi göstergeleridir. İnceleme alanında Karaçamlık Deresi'ni sağ yönde 240 metre öteleyen üzerinde Kale Fayı'na koşut ve koşut olmayan sintetik ve antitetik fay setleri saptanmıştır (Şekil 4a). Bu fayların da arazide 
normal fay karakterinde olduğu gözlenmiş olup, fayların güney blokları düşmüştür.

\section{MYRA ANTIKK KENTİ}

Doğuda Antalya Körfezi ile batıda Fethiye Körfezi arasında kalan ve güneyde Akdeniz'e doğru uzanan bugünkü Teke Yarımadası, Antik Dönem'de Likya olarak adlandırılmıştır. Tarihsel olarak bakıldığında; Likya'nın doğusunda Pamfilya, kuzeyinde Pisidya ve batısında ise Karya yer almaktadır (Şekil 2a). Antalya Körfezi, Antik Dönem'de "Pamfilya Denizi" olarak bilinmektedir. Teke Yarımadası, doğal coğrafi konumu göz önüne alındığında, farklı topoğrafik özelliklerine göre 4 farklı bölgeye ayrılabilir: Bu bölgeler; Doğu Likya, Orta Likya, Kuzey Likya ve Batı Likya'dır (Takmer, 2002). İnceleme alanı antik dönemdeki isimlere göre Orta Likya'da yer almaktadır. Myra Antik Kenti, Orta Likya da Antalya ili Demre ilçesi, Alakent mahallesi kuzeyinde kısmen kireçtaşları kısmen de Demre Ovası'nı oluşturan alüvyon birikintileri sınırına kurulmuştur. Myra Antik Kenti’ndeki arkeosismolojik çalışmalar halihazırda yüzeyde bulunan ve arkeologlarca yüzeye çıkarılan yapılar üzerinde gerçekleştirilmiştir. Antik kent faal yaşam sürdürüldüğü dönemde tüm Likya'nın başkenti olmuş ve tümüyle Roma dönemi yapılarını yansıtmaktadır. Kentin antik dönem sikkelerinden yola çıkılarak en erken M.Ö. 5. yüzyılda kurulduğu söylenebilir (Babelon, 1907; Kolb ve Tietz, 2001).

Antik kent çoğunlukla Demre Ovası'na kurulduğu için günümüzde büyük bölümü halen toprak altındadır. Myra Antik Kenti'nin 4,7 km güneybatısında yer alan Andriake, antik kentin limanıdır. Myra Antik Kenti’nin II. Theodosius döneminde Likya'nın başkenti ilan edilmesini takiben, liman yerleşimi Andriake, bölge metropolünün ana limanı konumuna gelmiştir (Foss, 1994).
$\mathrm{Bu}$ çalışma kapsamında, geçmişte ve günümüzde bölgesel açıdan bu denli önemli olan Myra Antik Kenti'ndeki tiyatro, kentin limanı olan Andriake'de ise; Granarium (Tahıl deposu), Dükkan ve Depolar, Kiliseler, Onurlandırma Anıtları ve Sinagog incelenmiş ve tarihsel depremlerin bu yapılar üzerinde yapmış olduğu hasarlar ve izler ortaya konulmaya çalışılmıştır. Öte yandan, fayların yeryüzündeki izlerinin belirlenmesinde topoğrafya, dere yataklarının ötelenmesi gibi jeomorfolojik veriler ile eski depremlerin tarihlerinin belirlenmesinde ise arkeolojik kalıntılardan yararlanılmıştır.

\section{DEPREMLERIN MYRA ANTIK KENTI'NE ETKİSI}

İnceleme alanı günümüzde olduğu gibi tarihsel dönemlerde de Güneybatı Anadolu kıyılarında yer alan kentler için bir köprü görevi görmüştür. Dolayısıyla bölgenin çevresinde zaman içerisinde önemli kentler kurulmuş ve bu kentleri bağlayan yollar gelişmiştir. Paleotektonik ve Neotektonik dönemler boyunca çok yoğun deformasyona uğramış olan kırık ve çatlaklı Üst Kretase kireçtaşları ile güncel alüvyon birikintilerinin sınırında bulunan Myra Antik Kenti, yüksek açılı aktif bir normal fay üzerinde kurulmuştur (Şekil 3). Myra Antik Kenti diğer kentler gibi tarihsel dönem depremlerinden oldukça fazlaca etkilenmiş ve zaman zaman yeniden restore edilmiştir. Ancak depremlerin ve doğal afetlerin şiddetli ve sürekli olmasından dolayı antik kentin zamanla terk edilmiş olduğu düşünülmektedir. M.S. 141 depremi bölgeyi yoğun şekilde etkilemiş, Myra Antik Kenti’ni görünür şekilde tahrip etmiştir. Rhodiapolis'li hayırsever Opramoas M.S. 141 depreminden sonra antik kente 100.000 dinarın üstünde bağış yaparak kentin yeniden görkemli halini almasını sağlamıştır (Coulton, 1978; Arca, 2002; Çevik 2010a-b). Gerek Myra Antik Kenti ve gerekse onun limanı olan Andriake'de KD-GB gidişli deformasyon zonunun içinde kalan, hasar 
gören ve incelenebilecek düzeyde olan yapılara aşağıda detaylı olarak değinilmiştir.

\section{Tiyatro}

Helenistik-Roma tipinde Likya'nın en büyük tiyatrosu olan at nalı biçimindeki cavea (Tiyatroda izleyicilerin oturduğu kısım; tribün), altta 29, üstte ise 9 oturma sırasına sahiptir(ÇevikveBulut, 2010). Tiyatro kentin kuzeyinde kireçtaşlarından oluşan yamaca dayalı olarak inşa edilmiştir. Tiyatronun genel görünümü yer yer tahrip olmasına rağmen, günümüzde çoğunlukla korunmuş bir görünüm sergilemektedir. Antik dönem tiyatrolarında, genelde oturma kısımlarının bittiği yerlerde büyük blokların yer aldığı bilinmektedir (Çevik ve Bulut, 2010). Tiyatro bu büyük bloklar ve sütunlar ile desteklenmektedir.

Arazide yapılan çalışmalarda, Tiyatronun güney kesimi tamamıyla hasar görmüş olup, sahnenin güneyi halen kalın bir alüvyon altındadır. KD-GB gidişli deformasyon zonunun içinde bulunan tiyatro bu zon boyunca yoğun hasar görmüştür. Myra Antik Kenti içerisindeki tiyatronun tribününün büyük bir çoğunluğu yamaca yaslanmış olup, ana kaya üzerinde yer aldığı için sağlam kalmıştır. Antik kentin masif kireçtaşlarından yapılı yamaca yaslanmış olan bu tribünlerde ise sadece çeşitli yönlerde hareketler meydana geldiği tespit edilmiştir. Demre Çayı'nın getirdiği alüvyonlar üzerinde yer alan ve Tiyatronun girişinde bulunan sahne ve tiyatronun iskeletini oluşturan bloklar, birbirinden ayrilarak kopmuş (Şekil 5b, 5c) ve saatin tersi yönünde dönmüştür. Aynı zamanda Antik tiyatronun sahne binasının ön ve arka bölümünde birbirlerine göre 4 metrelik bir morfolojik fark tespit edilmiştir (Şekil 5a).

Helenistik ve Roma Dönemi mimarileri göz önüne alındığında Myra Antik Kenti’ndeki tiyatroda görülen yıkılmaların ve yapılardaki ağır hasarların deprem etkisiyle meydana gelmiş olma olasılığ 1 çok yüksektir. Tiyatronun üst kısmında yer alan oturma basamaklarının bir kısmının, deprem etkisi ile sahne binasına doğru yuvarlandığ düşünülmektedir (Şekil 5d). Antik dönem tiyatrolarında özellikle analemma duvarlarında (izleyicilerin oturduğu kısmı destekleyen duvar), çok büyük hasar gözlenmektedir (Özdilek, 2016, Çevik vd., 2007). Ayrıca Helenistik Dönem'de inşa edilen, fay hattı üzerinde bulunan birbirine yakın Hierapolis ve Laodikeia kentlerinin tiyatrolarının kurulduğu alanların fay hattına denk gelmeleri nedeniyle oturma siraları her ikisinde de tamamen yıkılmıştır (Özdilek, 2016).

Tarihsel dönemlerde birbiri ardına gerçekleşen depremlerde doğabilecek hasarları en aza indirmek ve sağlam olması amaciyla bu bölümlere kuleler ile destekleme yapılmasına rağmen; Orta Likya'da bulunan diğer antik kentlerin arkeolojik kazırlarla gün yüzüne çıkarılan tiyatrolarında (Limyra, Rhodiapolis, Tlos vd.) olduğu gibi yıkımlar genelde bu kısımlarda yoğunlaşmaktadır. Mimarisiyle gerçek bir Roma Çağ $\breve{1}_{1}$ tiyatrosu olan Myra tiyatrosu M.S. 141 depremi sonrasında hasar gören bölümünün onarımı için Rhodiapolisli Opramoas tarafindan yapılan bağış ve yardımlarından dolayı Myra vatandaşı olarak onurlandırılmıştır (Borchhardt, 1975). Tiyatronun ilk yapım yılıyla ilgili belge olmamakla birlikte onarım tarihleri bilinmektedir. Çevik ve Bulut (2010)'a göre M.S. 141 depreminden sonra depreme dayanıklı olması için Arykanda antik kentinde olduğu gibi tiyatro sahne binası zemininin $\mathrm{K} 60^{\circ} \mathrm{D}$ doğrultulu sağ duvarı basınç azalmasını engellemek amacıyla kapatılmıştır (Şekil 5d). Arkeolojik kayıtlarda (Çevik ve Bulut, 2010) tespit edilen diğer onarım tarihi ise, M.S. 240 depreminden sonraki onarımdır. Aynı zamanda, kayıtlarda M.S. 344 depreminin Rhodos, Likya ve çevresindeki antik kentlerde yoğun hissedildiği ve bu depremden sonra antik kentlerin hasarlı bölümlerinin onarıldığ1 belirtilmektedir (Georgiades, 1904; Guidoboni vd., 1994; Duggan, 2004). 


\section{Tahıl Deposu}

Myra Antik Kenti'nin liman yapılarından olan Tahıl deposu (Granarium), Andriake liman yerleşiminin en görkemli yapısıdır. Cephesi kuzeye/limana bakan ve 8 bölümden oluşan liman yapıs1, çok iyi korunmuş olup duvar yükseklikleri $6,40 \mathrm{~m}$, kalınlıkları ise 1 metreye yakındır. Granarium kuzeye doğru eğimi olan kireçtaşından oluşan Kumdağı Tepe'nin yamaçlarının üzerine inşa edilmiştir. Yapı içinde ana kayanın genellikle doğal haliyle bırakıldığ 1 ve ana kaya boşluklarının kireç harc1 ve moloz taş ile doldurulduğu görülmüştür. Çevik ve Bulut (2010)'a göre, Granarium'un M.S. 119-138 yılları arasında inşa edildiği bilinmektedir.

Tarafimızdan yapılan gözlemlerde, Granarium'un kuzey yamacındaki $\mathrm{K} 48^{\circ} \mathrm{D}$ doğrultusundaki duvarda, saatin tersi yönünde dönme sonucu kuzeybatıya doğru eğimlenme, yamulmalar ve yıkılmalar tespit edilmiştir (Şekil 6f). Granarium'un duvarlarında gözlenen bu hasar, Roma döneminde su terazisi kullanıldığ bilindiğinden insan yapımı bir hata değildir (Çevik, 2011; Kişisel Görüşme).

Kültürel yap1 duvarların belli yönlerde korunarak diğer bazı yönlerde deformasyona uğramaları, yapılardaki bozulmaların ve bunu izleyen y1kılmaların deprem sarsıntılarının etkisiyle oluştuğuna dair bir kanıttır. Ayrıca bazı yapıların deprem dalgalarından çok fazla etkilenmesi, bazılarının ise daha az etkilenmesi ya da hiç etkilenmemesi duvar doğrultularının sismik sarsıntı yönlerine göre farklı konumda olmasından kaynaklanmaktadır. Bununla birlikte sismik hareketlerin yeterince güçlü olduğu durumlarda, sismik hareketin yönü ve yapıların uzanımları hangi yönde olursa olsun tüm yapılarda yıkılmalara neden olduğu gözlenmektedir (Şekil $2 \mathrm{~d}$ ve Şekil 6a).

\section{Dükkân ve Depolar}

Andriake limanının kuzeydoğusunda yer alan dükkân ve depoların, bölgedeki limanın tersanesine ait olduğu düşünülmektedir (Çevik ve Bulut, 2010). Dükkân ve depoların cepheleri güneye dönüktür ve her biri eşit ölçülere sahip değildir. Duvarlar moloztaş ya da harç kullanılarak örülmüş olup, yer yer duvar boyunca uzanan tuğla hatıllar depreme yönelik yapılan önlemlerden olduğu düşünülmektedir (Çevik ve Bulut, 2010).

Andriake'de dükkânlarda yapılan gözlemlerde, dükkân ve depoların $\mathrm{K} 46^{\circ} \mathrm{D}$ doğrultulu dış duvarların düşeyden $17^{0} \mathrm{KD}$ 'ya doğru eğimlendiği görülmektedir (Şekil 6b).

Antik kentlerdeki yapıları oluşturan taş blok, tuğla vb. malzemelerin yerlerinden oynamas1, itilmesi ve duvarların yamulmas1, deformasyonun deprem kaynaklı olduğunu işaret etmektedir. Gözlenen bu hasarda Kale Fayı'nın etkisinin yanında, liman koyunun oluşumunda aktif rol oynayan kuzeye eğimli normal fay olan Kekova Fayı'nın tavan bloğunun düşmesi sonucunda hasara uğramıştır (Şekil 6a). Bu yapılar M.S. 3 yy da inşa edilmiştir (Çevik ve Bulut, 2010). Bölgedeki dükkân ve depo yapıları önce M.S. 344 depremi, ardından M.S. 529-530 depreminden etkilenip hasar görmüş olmalıdır. Çünkü yapılardaki hasarlar ilk olduğu düşünülen depremden sonra yeniden kullanılmış devşirme malzemelerle onarılmış olduğu arkeologlarca saptanmıştır (Çevik ve Bulut, 2010).

\section{Kiliseler}

Andriake limanının kuzeyinde yer alan kilise, liman yerleşiminin zamanla alüvyon malzemeleri ile dolmas1 sonucunda kazanılan alan üzerine inşa edilmiştir. Duvarlar moloztaş ya da harç kullanılarak örülmüştür. Tekinalp (2000)'e göre, kiliseler M.S. 5 yüzyılın sonları ile 6 yüzyılın başlarında inşa edilmiş olmalıdır. 


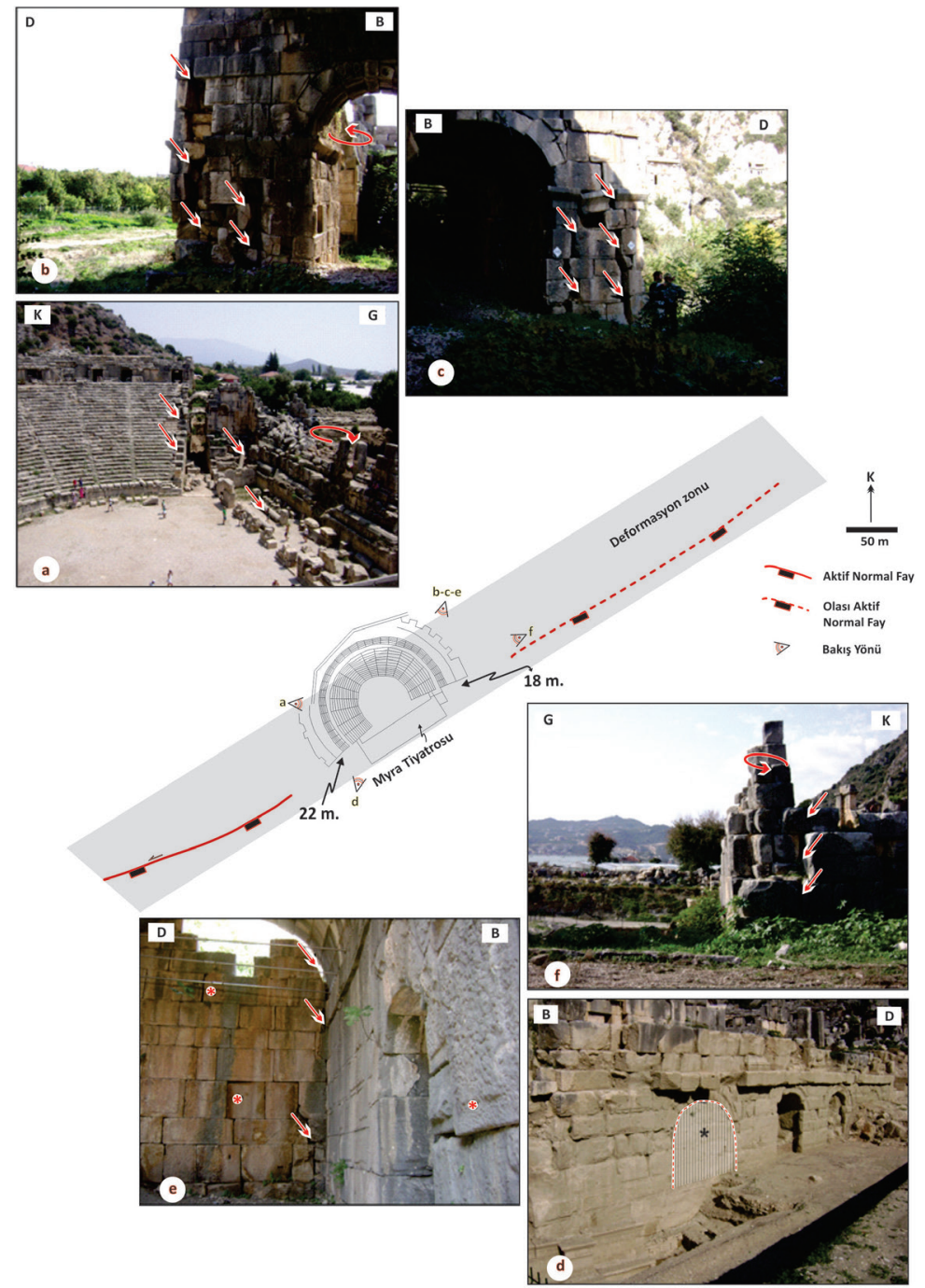

Şekil 5: Myra'daki yıkılmış arkeolojik kalıntıların planı (Çevik ve Bulut, 2010)'dan değiştirilerek). Plan aynı zamanda Şekil 5 a,b,c,d,e ve f'nin lokalitelerini içermektedir. a: Antik tiyatronun kuzeybatı tribünün ve sahne binasının saat yönünde dönmesi ve blokların KD-GB yönünde devrilmesinin görünümü. b-c: Tiyatronun sahne binasının giriş bölümündeki duvarların saatin tersi yönünde dönmesi ve bloklar ile duvarların üst kısımlarındaki aralığının artması sonucunda duvarın çökmesi. d: Şekildeki Asterisk MS 141 depreminden sonraki duvardaki restorasyonu görünümünü simgelemektedir. e: Şekildeki asteriskler saatin tersi yönünde yerdeğiştirmiş blokları, oklar ise blokların köşe kısımlarındaki hasarları simgelemektedir. f: Tiyatronun sahne binasının giriş kısımındaki duvarların kuzeybatıya doğru yönelmesinin ve saat yönünde yerdeğiştirmesinin görünümü.

Figure 5: Plan of ruptured archaeological relics at Myra, modified from Çevik (2010). Plan also shows locations of Figures $5 a, b, c, d$, e and $f$. a: Clockwise rotation and the moving of the blocks in NE-SW direction at the cavea in the northwest part of the ancient theater and the stage building $b$-c: Nearly collapsed entrance to the scene house of the theatre and increasing opening of the vertical joints between the building blocks towards the top of the wall indicating kinking of the wall because of anti-clockwise rotation the blocks. $d$ : Asterisks represent rebuilding area after the earthquake of $141 \mathrm{AD}$. e: Asterisks represent displaced blocks, while arrows indicate major fractures crossing the blocks or affecting the corners of the blocks. $f$ : The view of the walls of the entrance of the stage building of the theater towards northwest and displacing clockwise. 


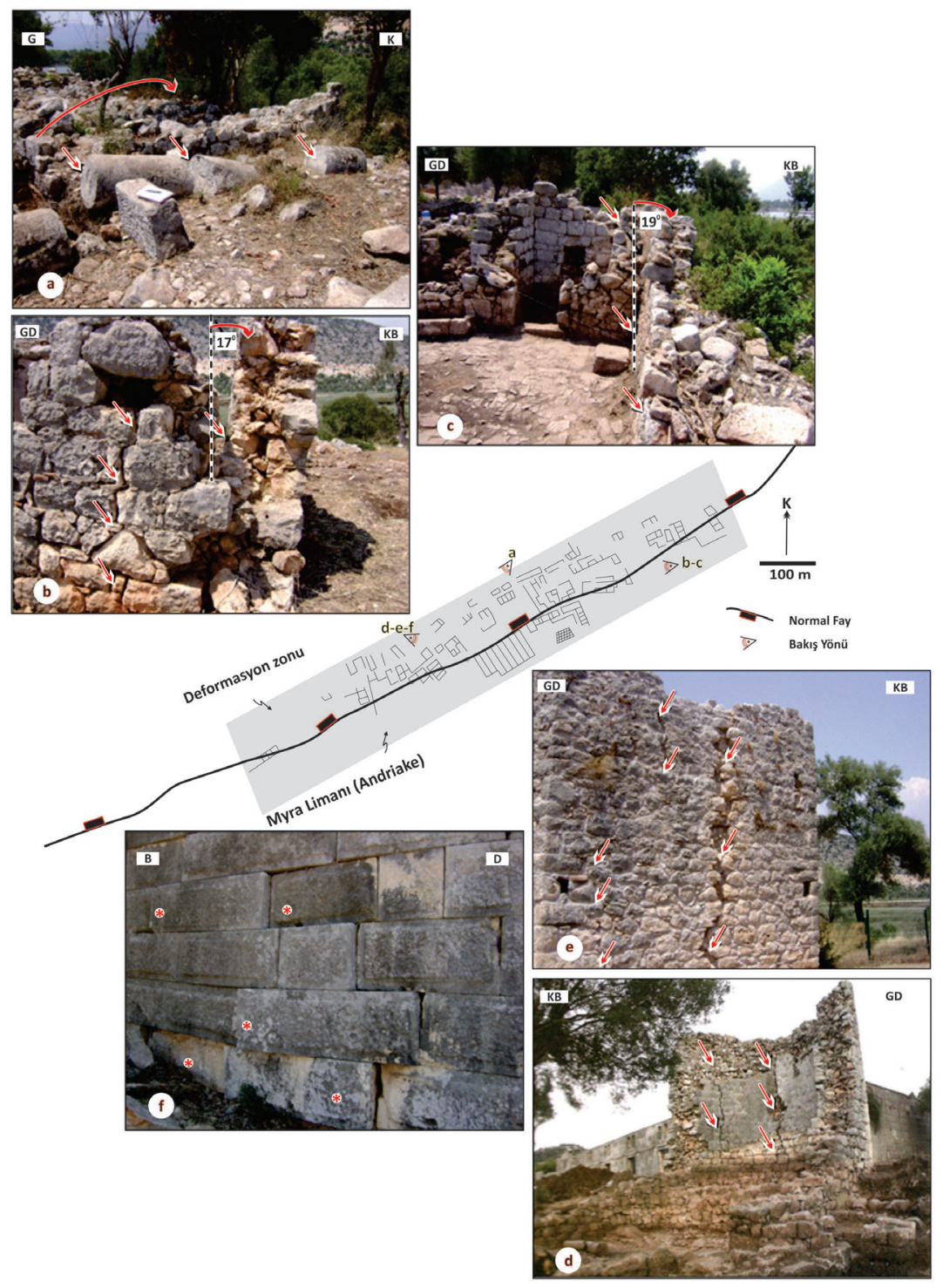

Şekil 6: Myra'nın limanındaki yıkılmış arkeolojik kalıntıların planı (Çevik ve Bulut, 2010)'dan değiştirilerek). Plan aynı zamanda Șekil 6 a, b, c, d, e ve f'nin lokalitelerini içermektedir. a: Onurlandırma anıtları KD-GB istikametinde devrilmiş ve küçük parçalara ayrılmıştır. b: dükkân ve depoların $\mathrm{K} 46^{\circ} \mathrm{D}$ doğrultulu dış duvarların $17^{0}$ ile kuzeydoğuya doğru eğimlenmesi. c: yapının $\mathrm{K} 18^{\circ} \mathrm{D}$ doğrultulu dış duvarının kuzeydoğuya doğru eğimlenmesi ve sistematik çatlamaların görünümü. d-e: Sinagog yapısının güneye bakan $\mathrm{K} 42^{\circ} \mathrm{D}$ doğrultulu apsis binasında yaklaşık KD-GB doğrultulu sistematik çatlamalar. f: Granarium'un $\mathrm{K} 48^{\circ} \mathrm{D}$ doğrultusundaki duvarda, saat yelkovanı tersi yönünde dönme sonucu kuzeybatıya doğru eğimlenme, yamulmalar ve yıkılmaların görünümü.

Figure 6 a: Plan of ruptured archaeological relics at port of Myra, modified from Çevik ve Bulut, 2010). Plan also showing locations of Figures $6 a, b, c, d$, e and $f$. $a$ : An honorary monument were overturned in the NE-SW direction and divided into small pieces. $b$ : Tilting the outer walls of the ancient buildings along the $N 46^{0} E$ to the northeast direction with $17^{\circ} . c$ : The northward tilting and systematic deformation of the N1 $8^{0} E$-oriented outer wall. d-e: Approximate NE-SW directional systematic deformation in the southward-facing $N 42^{\circ} E$-oriented apsis of the synagogue structure. $f$ : In the wall of Granarium's $N 48^{\circ} E$ direction, the appearance of tilting, twisting and collapsing towards since northwest moving of the anti-clockwise blocks. 
Andriake'de kiliselerde yapılan gözlemlerde, yapının K18ㅁ doğrultulu dış duvarının kuzeydoğuya doğru eğimlendiği ve sistematik çatlamalara maruz kaldığı belirlenmiştir (Şekil $6 c)$.

Daha öncede söz edildiği üzere, antik kentlerdeki yapıları oluşturan taş blok, tuğla vb. malzemelerin yerlerinden oynamas1, itilmesi ve duvarların belirli yönlerde sistematik yamulması, çatlaması deformasyonun deprem kaynaklı olduğunu işaret etmektedir. Buna göre, inceleme alanındaki kiliselerin M.S. 6 yy'dan sonraki depremlerden etkilendiği düşünülmektedir.

\section{Onurlandırma Anıtları}

Dükkan ve depoların batı bitişiğindeki dar sokaktan sonra yer alan iki adet anıt kuzeye bakmakta olup, anıta ait bloklar geç dönemde kuzeyde yer alan yapıda örgü malzemesi olarak kullanıldığ1 ve anıtların M.S. 4 yy sonlarına kadar ayakta kaldığ1 arkeologlarca yapılan kazılardan bilinmektedir (Çevik ve Bulut, 2010).

Andriake liman yapılarında yapılan detaylı gözlemlerde onurlandirma anıtları, KD-GB istikametinde devrilmiş ve küçük parçalara ayrılmıştır (Şekil 6a).

Yeterli derecede sağlam yapılmamış olan yapılarda, yatay ve düşey kuvvetlerin etkisiyle yer yer çökmeler ya da şiddetli çatlamaların sonucunda devrilme ve yıkılmalar meydana gelebilmektedir. Antik kentlerdeki sütunlu yapıların sütun çemberlerindeki çatlama ve ayrılmalar, sütunların bir şerit halinde sıralı bir şekilde yıkılması, bu kentlerin geçmişte bir ya da birden fazla depremden etkilenmiş olabileceğini düşündürmektedir. Dolayısıyla, anıtlardaki bu deformasyonlar kentte eskiden meydana gelen depremler hakkında ipucu oluşturmaktadır. Arkeolojik bulgulara göre (Çevik ve Bulut, 2010) 4. yy sonlarına kadar sağlam olan bu anıtlar M.S. 4 yy'dan sonra meydana gelmiş bir veya birden fazla depremde hasar görmüş olmalıdırlar.

\section{Sinagog}

Andriake liman yapılarından olan sinagog, Granarium'un (Tahıl deposu) batı köşesi önünde, limana bakar biçimde konumlandırılmıştır. Arkeologlarca yapılan kazı sonuçlarına göre sinagog binasının antik kente sonradan eklendiği anlaşılmıştır. Yapıda bulunan sikkeler en erken M.S. 4 yy'a dayanmaktadır (Çevik ve Bulut, 2010).

Andriake liman yapilarında sinagogda yapılan gözlemlerde, Sinagog yapısının güneye bakan $\mathrm{K} 42^{\circ} \mathrm{D}$ doğrultulu apsis binasında yaklaşık KD-GB doğrultulu sistematik çatlamalar ve ayrılmalar tespit edilmiştir (Şekil 6d, 6e). Bunların büyük bir çoğunluğu günümüzde arkeologlarca restore edilmiştir. Sinagog binasının sadece apsisi günümüze kadar ulaşmıştır. Diğer bina yapıları ise yıkılmış ve bazıları da depremlerin etkisiyle bölgenin jeomorfolojik değişimleri sonucunda alüvyon altında kalmıştır.

Singogda gözlenen sistematik çatlakların yan yana birkaç tuğlayı kesen boylu boyunca uzanan çatlaklar olduğu ve heyelan ya da statik yüklerin etkisinden çok sismik sarsıntıların etkisi ile meydana gelmiş olabileceği düşünülmektedir.

Yapının, kuzeyinden ve güneyinden hem kazı öncesinde hem de sonrasında çekilen fotoğraflardan yararlanarak duvarların belli yönde deforme olmadan aynen korunmaları, belli yönlerde ise deformasyon sonucu düşme, çatlama, ayrılma göstermeleri depremler tarafından hasara uğratıldığının kanıtıdır. Buna göre, arkeolojik bulgulara göre yapımı en erken M.S. 4. yy olan bu sinagog, M.S. 4 yy'dan sonra meydana gelmiş depremlerden oldukça hasar görmüş olmalıdır.

\section{TARTIŞMA VE SONUÇLAR}

Teke Yarımadası'nın güneydoğusundaki Demre Ovası'nda yer alan Myra Antik Kenti, normal bir fay olan Kale Fayı'nın üzerine kurulmuştur. Geniş ölçekte bakıldığında Fethiye-Burdur Fay Zonu ve 
Pliny-Strabo hendekleri arasındaki bölgede kalan Demre Ovası'nda, aletsel ve tarihsel dönemlerde bu fay zonları üzerinde ve yakın çevresinde yoğun depremler meydana gelmiştir. Fayların üretebileceği depremlerin büyüklüğü ve düşey yer değiştirmenin miktarı, fayın türüne, kinematik özelliklerine, fayın uzunluğuna göre değişiklik göstermektedir (Peacock ve Sanderson, 1991 ve Wells ve Coppersmith, 1994). Myra Antik Kentine yoğun hasar verdiği düşünülen $12 \mathrm{~km}$ ile $20 \mathrm{~km}$ uzunluğunda iki segmentten oluşan Kale Fayı ve 17 km uzunluğundaki Kekova Fayı kırıldığında sırasıyla Wells ve Coppersmith (1994) eşitliği göz önünde bulundurulduğunda, bu fayların $\mathrm{M}_{\mathrm{w}}: 6,28$, $M_{w}: 6,58$ ve $M_{w}: 6,48$ büyüklüğündeki depremleri üretme potansiyeline sahip olduğu düşünülebilir (Çizelge 3).
Demre ve çevresinde bulunan aktif faylardan Fethiye Burdur Fay Zonu, Kale Fay1, Kekova Fay1 ve bunların ürettiği deprem dalgalarının değişik dönemlerde Myra Antik Kenti'ni etkilediği düşünülmektedir. Kale Fayına ait düzlemlerden alınan kinematik verilerle fayı oluşturan asal gerilme eksenleri tespit edilmiş olup, genişleme yönü ise KKB-GGD istikametinde olduğu görülmektedir. Saptanan bu yönler, Güneybatı Anadolu'da gerilme ve sıkışma yönlerini aşamalı olarak bölgelere ayıran Över, vd. (2016) çalışması ile de örtüşmektedir.

Fayların uzanımları ile antik yapılardaki deformasyonların yönlerinin ilişkisi, tarihsel depremlerin oluşturduğu şiddetli dalgaların kentin üzerinde kurulduğu ana kaya türüne ve

Çizelge 3. Kale ve Kekova Faylarının kinematik özellikleri ve üretebileceği deprem büyüklükleri (Emre vd. 2016'dan değiştirilerek).

Table 3. The kinematic structure of the Kale and Kekova Faults and its can be potential produce earthquake (after Emre et al. (2016).

\begin{tabular}{|c|c|c|c|c|}
\hline & Uzunluk $(\mathrm{km})$ & Doğrultu/Eğim & Rake Açısı & Üretebileceği Deprem $\left(\mathrm{M}_{\mathrm{w}}\right)$ \\
\hline \multirow{2}{*}{ Kale Fayı } & 12 & K62D/60GD & $?$ & 6,28 \\
\cline { 2 - 5 } & 20 & K65D/65GD & $64-85 \mathrm{D}$ & 6,58 \\
\hline Kekova Fay1 & 17 & K60D/70KB & $?$ & 6,48 \\
\hline
\end{tabular}

Duggan (2004)'ün çalışmasında M.S. 141 depremine ait izosismik haritasında da görüldügü gibi bu depremin sadece Myra Antik Kenti'nde değil tüm Likya ve Karya çevresinde yoğun biçimde hissedildiği görülmektedir. Hierapolis, Laodikeia, Priene, Knidos ve Lagina Antik kentlerinde olduğu gibi Myra Antik Kenti'nin de faylı dokanak üzerinde kurulması ve kentlerin büyük bir bölümünün fayın tavan bloğunda bulunan alüvyonal birimler üzerinde bulunmasından dolayı antik kentlerde en çok hasar alan bölgeler bu alanlarda yoğunlaşmıştır. onun üzerinde bırakmış olduğu etkiye, yapıların üretildiği malzemeye gibi sayısız parametrelere göre değişiklik gösteren ve arkeosismolojik çalışmalarda sık kullanılan değerlendirme kriterlerinden bazılarıdır (Karcz ve Kafri, 1978; Stiros, 1996; Hancock ve Altunel, 1997; Galadini ve diğ. 2006; Marco ve diğ., 2008; Bottari ve diğ., 2009; Karabacak ve diğ., 2013; Karabacak, 2016).

Yapılan gözlemler sonucunda Myra Antik Kenti'nin Kale Fayı'nın gidişi ile uyumlu KDGB uzanımlı deformasyon zonunda kaldığ 1 ve bu zonun içerisindeki deforme olmuş yapıların ise 
sistematik olarak belirli bir yöne doğru devrilen sütunlar, yıkılmış kolonlar, dönmüş ve eğimlenmiş bloklar şeklinde fay zonu içinde geliştikleri görülmüştür. Ayrıca bazı yapı duvarlarındaki taş bloklarda yer alan çatlaklarda gözlenen eski harçlar önceden de aynı duvarlarda çatlamaların, ayrılmaların meydana geldiğini ve eski dönemde meydana gelen depremlerden sonra çatlakların doldurularak onarıldığını göstermektedir. Tarihsel dönem deprem kayıtları incelendiğinde, M.S. 6068, M.S. 141, M.S. 344, M.S. 529-530 ve 7 yy. depremlerinin Myra Antik Kenti'ni de içine alan tüm Likya kıyılarını etkilediği görülmektedir. Ancak bu depremlerden M.S. 141, M.S. 240 ve M.S. 344 depremlerinin Myra Antik Kenti'nin tiyatrosunu ve limanını hasara uğrattığı ve kentin yapılan yardımlarla yeniden onarıldığ arkeologlarca tespit edilmiştir.

Rodríguez-Pascua ve diğ. (2011 ve 2013) yılındaki çalışmasında antik kentlerde gözlenen bu hasarların şiddetlerini, EMS-98 (Grünthal, 1998) ve ESI-07 (Michetti ve diğ., 2007) dünya ölçeğinde şiddet cetvelleriyle birlikte incelemiş, aynı zamanda Karabacak ve diğ. (2013) ve Karabacak, (2016) yıllarındaki çalışmalarında ise bu skalalara ek olarak antik kentlerin üzerinde kurulduğu zeminlerin özelliklerini göz önünde bulundurarak değerlendirmiştir.

Antik kentlerdedepremlerin etkisiylegözlenen bu hasarların şiddet dereceleri, depremlerin büyüklüğüne, odak derinliği ve uzaklığına bağlı olmakla birlikte, kentin kurulu olduğu ana kaya özelliklerine, antik yapıların bileşimine ve yeraltı suyu seviyesine göre değişiklik gösterebilmektedir (Stiros, 1996; Karabacak ve diğ., 2013). Tüm bu veriler göz önünde bulundurulduğunda Myra Antik Kenti'nde alüvyon zemin üzerinde bulunan tiyatro ve limanda gözlenen yoğun deformasyonlar, şiddetin VII-VIII olduğunu göstermektedir.

Bat1 ve Güneybatı Anadolu'da normal faylarda yapılan çalışmalarda depremlerin tekrarlanma periyotları 150-2000 y1l arasinda değişiklik göstermektedir (Özkaymak vd., 2011, Altunel vd. 2009, Mozafari vd., 2016). Arkeolojik verilere göre elde edilen tarihsel depremlerin ortalama meydana gelme süresinin ilk dört deprem için 100 yıl ve son üç deprem için ise 200 yıl olduğu görülmektedir. Bu sonuçların da Batı ve Güneybatı Anadolu için hesaplanan değerler ile benzerlik gösterip göstermediğini bulabilmek için bu depremlerin aynı fay zonu üzerinde oluştuğunu bilmemiz gerekmektedir.

Bu depremlerin günümüzde diri olan Kale Fay1 ve Kekova Fayı'nın ürettiği depremler olabileceği düşünülmektedir, ancak uygun alandan yapılacak hendek tabanlı paleosismoloji çalışmaları ve fay yüzeyleri üzerinde kozmojenik yaşlandırma çalışmaları ile hangi depremin hangi fay tarafından üretildiği saptanarak bu kanı doğrulanabilir ve ileriki tarihlerde olabilecek depremler için tekrarlanma aralıkları hesaplanabilir.

\section{KATKI BELIRTME}

Bu çalışma, Karadeniz Teknik Üniversitesi Bilimsel Araştırma Projeleri Birimi tarafından birinci yazarın, ikinci yazarın danışmanlığında 2010-2012 y1lları arasında yürütülen KTUBAP-2010.112.005.11 no.lu yüksek lisans tezi projesi kapsamında desteklenmiştir. Yazarlar arkeolojik kazı sonuçları ile ilgili değerli verileri paylaştıkları için Akdeniz Üniversitesi'nden Nevzat Çevik, Michael Duggan, Afşin Aygün ve tüm arkeolojik kazı ekibine, ayrıca makaleye yaptıkları kritik yorumlardan dolayı Dokuz Eylül Üniversitesi'nden Bora Uzel, Ökmen Sümer'e ve makalenin bilimsel değerinin artırmak adına yaptıkları katkılardan dolayı Selim Özalp, Halil Gürsoy ve Volkan Karabacak'a teşekkür ederler.

\section{EXTENDED SUMMARY}

Turkey is one of the unique country by accommodating various settlements in its long history. Most of the antique cities in Turkey 
were established along the active fault zones. Archaeoseismological investigations can contribute impressively to a better characterization of the poorly known past earthquakes in SW Anatolia. Ancient city of Myra and Andriake (port of Myra) are sitted SW Anatolian, NW of Demre basin. Demre Basin (Antalya) which is restricted to active faults controlled by Kale Fault and Kekova Faults which are normal faults inclined to the south and reverse faults inclined to the north.

According to our geological mapping studies, Ancient city of Myra is located on trending of $N 65^{\circ} \mathrm{E}$, an approximately $32 \mathrm{~km}$ long, high angle normal faults (Kale Fault) and composes of two fault segments. The $20 \mathrm{~km}$ length the first segment, which is believed to have caused severe damage to Myra Ancient City during historical and instrumental periods. Between Kale and Kapakli region first segment of the Kale Fault can be traced along the scarp. The $\sim 12 \mathrm{~km}$ length the second segment starts from Bogazclk region and continues along the southwestern coast of Strongili Island on the Mediterranean Sea. These two segments of the Kale Fault are connected to each other via relay ramp. Over the 200 earthquakes with a magnitude greater than $M_{w}: 3$ have been occured and 7 of these earthquakes are larger than $M_{w}: 5$ in the vicinity of the Demre Basin. According to historical records and archaeological datas, Ancient City of Myra was affected by 60-68 A.D., 141 A.D., 240 A.D., 344 A.D., 529 A.D. and 7th century earthquakes. These earthquakes are concentrate on active faults located on the Teke Penunsula and around.

Analysis of the damaged relics indicates that the nekropolis of Myra, amphitheatre and the port of Myra were ruptured NE-SW trending damage zone linked with Kale Fault and Kekova Fault that shows clear evidence for displacements since the 141, 240 and 344 AD earthquakes. Moreover, stage building a level morphological difference of $4 \mathrm{~m}$. between the front and backside. Lastly, nearly all archaeological relics show different degrees of earthquake related damage and the city was affected by at least three historical earthquakes in the Holocene time interval.

Two segments of the Kale Fault have the potential to produce an earthquake with a magnitude of $M_{w}=6.58, M_{w}=6.28$, respectively. Kekova Fault has also the potential to produce an earthquake with a magnitude of $M_{w}=6.48$. It can be suggested that if the segments of the Kale Fault are combined with each other via relay ramp to produce a single earthquake, $M_{w}=6.7$ earthquake can be produced. Based on these results and kinematic data, NW-SE-directed extension is mainly responsible for the recent faulting along the Kale Fault. For the future studies, trench based palaeoseismological studies should be performed along the Kale and Kekova Fault to decipher evidence for the Holocene activities. Besides this, to determine earthquake recurrence intervals and estimate the long-term slip-rates should be performed cosmogenic dating studies on these fault scarp.

\section{ORCID}

Mustafa Softa D

https://orcid.org/0000-0001-5064-9260

Mehmet Turan $\mathbb{D}$

https://orcid.org/0000-0001-9108-6695

Hasan Sözbilir (D)

https://orcid.org/0000-0002-3777-4830

\section{DEĞINIILEN BELGELER}

Akyüz, S. and Altunel, E., 2001. Geological and archaeological evidence for post-Roman earthquake surface faulting at Cibyra, SW Turkey, Geodinamica Acta. 14(3), 95-101.

Altunel, E., 1998. Evidence for damaging historical earthquakes at Priene, Western Turkey, Turkish J. Earth Sci., 7(1), 25-35.

Altunel, E., Akyüz, S., Meghraoui, M., Kıyak, N.G., Karabacak, V., Yönlü, Y., Yalçıner, C. Ç., 2009. Büyük Menderes Fay Zonunun Arkeosismolojisi 
ve Paleosismolojisi, TÜBİTAK Projesi Sonuç Raporu, 208 syf. Proje No: 105Y348.

Altınok, Y., Alpar, B., Özer, N. and Aykurt, H., 2011. Revision of the tsunami catalogue affecting Turkish coasts and surrounding regions, Natural Hazards and Earth System Sciences 11(2), 273291.

Ambraseys, N. N., Finkel, C. F., 1995. The seismicity of Turkey and adjacent areas. A historical review, 1500-1800, Eren Press, Istanbul, Turkiye.

Arca, E.N.A., 2002. Lykia'li bir Eurgetes: Opramoas, Sahin, S-Adak, M.(Eds), Likya İncelemeleri 1, 79-90.

Ayhan, E., Aslan, E., Sancaklı, N., Uçer, S. B., 1983. Türkiye ve Dolayları Deprem Kataloğu 18811980, Boğaziçi Üniversitesi Yayınları, İstanbul, Türkiye.

Babelon. E., 1907. Traite des monnaies grecques et romaines, Membre de l'Institut de France, Paris.

Barka, A., Reilinger, R., 1997. Active tectonics of the Eastern Mediterranean region: Deduced from GPS, neotectonic and seismicity data, Annals of Geophysics 40(3), 587-610.

Bayburtluoğlu, C., 2003. Yüksek Kayalığın Yanındaki Yer Arycanda, Homer Kitabevi, İstanbul, Turkiye.

Bayburtluoğlu C., 2004. Lykia, Suna-İnan Kıraç Akdeniz Medeniyetleri Araştırma Enstitüsü, Antalya.

Bean. G.E., 1978. Lycian Turkey: An archaeological guide, Benn and Norton Publications, London, UK.

Borchhardt, J., 1975. Myra: Eine lykische Metropole in antiker und byzantinischer Zeit, IstForsch, 30, 81-86.

Bottari, C., Stiros, S.C., Teramo, A., 2009. Archaeological evidence for destructive earthquake in Sicily between 400 B.C. and A.D. 600, Geoarchaeology, 24(2), 147-175 pp.

Bozcu, M., Yağmurlu, F. and Şentürk, M., 2007. Some Neotectonic and Paleoseismological features of the Fethiye-Burdur Fault zone, SW Anatolia, Geological Engineering. 31(1), 25-48.

Coulton, J.J., 1978. Opramoas and Anonymous Benefactor, The Journal of Hellenic Studies, 107, 171-178.

Çevik, N., 2010a. The Sunken Metropolis of St Nicolas," Current World Archaeology 41(1), 1825 .
Çevik, N., 2010b. The First Season of Excavations in Myra and Andriake, ANMED, 8, 55-60.

Çevik, N., 2011. Kişisel Görüşme. Akdeniz Üniversitesi, Antalya, Türkiye

Çevik, N., Bulut, S., 2010. İkinci Kazı Sezonunda Myra Ve Limanı Andriake, Arkeolojisinden Doğasına Myra/Demre ve Çevresi, Çevik, N., (Editor), Kültür ve Turizm Bakanlığı yayinlari, Ankara, Türkiye, 25-115.

Çevik, N., Kızgut, İ., Bulut, S., 2007. Excavations at Rhodaipolis in 2006: The First Campaign. ANMED, 59-67.

Demirtaş, R., 2005. Antalya ve çevresindeki tarihsel depremler, Antalya'nın Jeolojisi ve Doğal Afetleri Konferansları, TMMOB Jeoloji Odası Yayınları, Antalya, Türkiye.

Duggan, T.M.P., 2004. A Short Account of Recorded Calamities (Earthquakes And Plagues) in Antalya Province and Adjacent and Related Areas over the Past 2,300 Years an Incomplete List, Comments and Observations. ADALYA VII, 123-164.

Duggan, T.M.P., 2005. Suplementary Data to be Added to the Chronology of Plague and Earthquakes in Antalya Province and in Adjacent and Related Areas, AKMED 8(1), 357-398.

Dumont, J.F. ve Kerey, E,. 1975. Eğirdir Gölü Güneyi'nin Temel Jeolojik Etüdü: Türkiye Jeol. Kur. Bült., 18/2, 169-174.

Emre, Ö., Duman, T. Y., Olgun, Ş., 2012. 1:250.000 Ölçekli Türkiye Diri Fay Haritası Serisi, Fethiye (NJ 35-16) Paftası Serisi. No: 39, Maden Tetkik ve Arama Genel Müdürlüğü, Ankara.

Erel, T. L. and Adatepe, F., 2007. Traces of historical earthquakes in the ancient city life at the Mediterranean region, Journal of the Black Sea/ Mediterranean Environment 13(1), 241-252.

Ersoy, S., 1990. Batı Toros (Likya) Napları'nın Yapısal Öğelerinin ve Evriminin Analizi. Jeoloji Mühendisliği Dergisi, 37, 5 - 16.

Eyuboglu, Y., Santosh, M., Dudas, F. O., Akaryal1, E., Chung, S. L, Akdag, K. and Bektas, O., 2013. The nature of transition from adakitic to non-adakitic magmatism in a slab-window setting: A synthesis from the Eastern Pontides, NE Turkey, Geoscience Frontiers 4(4), 353-375.

Foss, C., 1994. The Lycian Coast in the Byzantine Age, Dumbarton Oaks Papers, 48, 1-52. 
Galadini, F., Hinzen, K.G., Stiros, S., 2006. Archaeoseismology: Methodological issues and procedure, Journal of Seismology, 10(4), 395-414.

Georgiades, S.A., 1904. About earthquakes and antiseismic constructions. Publ. S. Kousoulinou, Athens, $306 \mathrm{pp}$.

Grünthal, G., 1998. European macroseismic scale, European Seismological Commission, Subcommission on Engineering Seismology, Working Group Macroseismic scales, Luxembourg, 99 pp.

Guidoboni, E., Comastri, A., Traina, G., 1994. Catalogue of ancient earthquakes in the Mediterranean area up to the 10th century, Instituto Nazionale di Geofisica, Rome, France, ING-SNA.

Günay, Y., Bölükbaşı, S., Yoldemir, O., 1982. Beydağlarının Stratigrafisi ve Yapısı, Türkiye Altıncı Petrol Kongresi Bildiriler Kitabı, Ankara, 91-101.

Gürer, A., Bayrak, M., Gürer, Ö. F., 2004. Magnetotelluric images of the crust and mantle in the southwestern Taurides, Turkey. Tectonophysics 391(1), 109-120.

Hall, J., Aksu, A. E., Yaltırak, C., Winsor, J. D., 2009. Structural architecture of the Rhodes Basin: A deep depocentre that evolved since the Pliocene at the junction of Hellenic and Cyprus Arcs, eastern Mediterranean, Marine Geology 258(1), 24-47.

Hancock, P.L., Altunel, E., 1997. Faulted archaeological relics at Hierapolis (Pamukkale), Turkey, Journal of Geodynamics, 24(1-4), 21-36.

Jackson, J., McKenzie, D. 1984. Active tectonics of the Alpine-Himalayan Belt between western Turkey and Pakistan, Geophys. J. R. astr. Soc. 77, 185 -264 .

Karabacak, V., Yönlü, Ö., Dökü, E., Kryak, N.G., Altunel, E., Özüdoğru, Ş., Yalçıner, C.Ç., Akyüz, H.S. 2013. Analysis of seismic deformations at the Kibyra Roman stadion. SW Turkey. Geoarchaeology, 28, 531-543.

Karabacak, V., 2011. Geological, geomorphological and archeoseismological observations along the Cibyra Fault and their implications on the regional tectonic of SW Turkey, Turk J Earth Sci. 20(4), 429-447.

Karabacak, V., 2016. Seismic damage in the Lagina sacred area on the Mugla Fault: a key point for the understanding of the obliquely situated faults of western Anatolia, J. Seismology 20, 277-289.
Karcz, I., Kafri, U., 1978. Evaluation of supposed archaeoseismic damage in Israel, J. Archaeol. Sci. 5, 237-253.

Koçyiğit, A., 1981. Hoyran Gölü Yöresinin (AfyonIsparta) Stratigrafik ve Tektonik Özellikleri: Ankara Üniv. Fen Fak., 1-30.

Koçyiğit, A. 1983. Hoyran gölü (Isparta büklümü) dolayının tektoniği. TJK. Bült., 26(1), 1-10.

Kolb, F., Tietz, W., 2001. Zagaba: Munzpragung und politische Geographie in Zentrallykien, Chiron, 31, 347-416.

Konak, N., Şenel, M., 2002. Geological Map of Turkey in 1/500,000 scale: Denizli Sheet, Mineral Research and Exploration Directorate of Turkey Press, Ankara, Turkey.

Kondorskaya, N. V., Ulomov, V. I., 1999. Internet Site for Data on Earthquakes, Special catalogue of earthquakes of the Northern Eurasia (SECNE), http://socrates.wdcb.ru/scetac/andhttp://www. seismo.ethz.ch/gshap/neurasia/nordasiacat.txt (Last accessed May 2017)

Marco, S., Kamai, R., Hatzor, Y.H., Wechsler, N., Katz, O., 2008. Constraining location and size of historical earthquakes using mechanical analyses of damaged archeological sites: examples from Dead Sea Fault, European Seismological Commission ESC 2008, 31st General Assembly, Crete, 7-12 pp.

Michetti, A.M., Esposito, E., Guerrieri, L., Porfido, S., Serva, L., Tatevossian, R., Vittori, E., Audemard, F., Azuma, T., Clague, J., Comerci, V., Gürpınar, A., Mc Calpin, J., Mohammadioun, B., Mörner, N.A., Ota, Y., Roghozin, E., 2007. In Memorie Descrittive della Carta Geologica d'Italia, Environmental Seismic Intensity Scale 2007, E. Vittori, L. Guerrieri (eds.), (Servizio Geologico d'Italia, Dipartimento Difesa del Suolo, APAT, SystemCart Srl, Roma, Italy), 53 pp.

Mozafari, A. N., Sümer, Ö., Tikhomirov, D., Özkaymak, Ç., Uzel, B., Ivy-Ochs, S., Vockenhuber, C., Sözbilir, H., Akçar, N., 2016. Holocene Time-slip history of normal fault scarps in western Turkey: $36 \mathrm{Cl}$ surface exposure dating. AGU Fall Meeting, 12-16 December, San Francisco, USA.

Öner, E., 1998. Zur Geomorphologie der Eşen Deltaebene und des Antiken Hafens von Patara in der Südwesttürkei. Adalya III, 207-220.

Ötüken, S.Y., 1996. Ortaçağ Araştırmaları ve Aziz Nicolas Kilisesi Kazısı. Adalya1, 73-87. 
Över, S., Özden, S., Pınar, A., Yılmaz, H., Kamacı, Z., Ünlügenç, U.C., 2016. Late Cenozoic stress state distributions at the intersection of the Hellenic and Cyprus arcs, SW Turkey. J Asian Earth Sci, 132, 94-102.

Özdilek, B., 2016. An Overview of Lycian Theaters, The Journal of MCRI, Cedrus IV, 139-185.

Özhan, G., 2004. Antalya Körfezi Jeolojik ve Tektonik Özellikleri. Antalya'nın Jeolojisi ve Doğal Afet Konferansları TMMOB Jeoloji Müh. Odası Yayınlar1, 87, 27-36, Antalya.

Özkaymak, Ç., Sözbilir, H., \& Uzel, B., 2011. Geological and palaeoseismological evidence for late Pleistocene-Holocene activity on the Manisa Fault Zone, western Anatolia. Turkish Journal of Earth Sciences, 20, 1-26.

Peacock, D.C. P., Sanderson, D. J., 1991. Displacements, segment linkage and relay ramps in normal fault zones, Journal of Structural Geology, 13(6), 721733.

Poisson, A., 1977. Recherches Geologiques Dans Les Taurides Occidentales (Turquie). These Doct d'Etat, Univ. Paris- Sud, Orsay, France (unpublished).

Rodríguez-Pascua, M.A., Pérez-López, R., Silva, P.G., Giner-Robles, J.L., Garduño-Monroy, V.H., Reicherter, K., 2011. A Comprehensive Classification of Earthquake Archaeological Effects (EAE) for Archaeoseismology, Quaternary International, 242, 20-30.

Rodríguez-Pascua, M.A., Silva, P.G., Pérez-López, R., Giner-Robles, J.L., Martín-González, F., Perucha, M.A., 2013. Preliminary intensity correlation between macroseismic scales (ESI07 and EMS98) and Earthquake archaeological effects (EAEs), Proceedings of the 4th International INQUA Meeting on Paleoseismology, Active Tectonics and Archeoseismology (PATA), 9-14 October 2013, Aachen, Germany.

Rotstein, Y., and A. L. Kafka, 1982. Seismotectonics of the southern boundary of Anatolia, eastern Mediterranean region, subduction, collision and arc jumping, J. Geophys. Res., 87, 7694-7706.
Soysal, H., Sipahioğlu, S., Kolçak, D. and Altınok, Y., 1981. Türkiye ve Çevresinin Tarihsel Deprem Kataloğu (M.Ö. 200-M.S. 1900), Tübitak Yayınları, İstanbul.

Sözbilir, H., Sarı, B., Uzel, B., Sümer, Ö. and Akkiraz, S., 2011. Tectonic implications of transtensional supradetachment basin development in an extension-parallel transfer zone: The Kocacay Basin, western Anatolia, Turkey, Basin Research 23(4), 423-448.

Stiros, S.C., 1996. Identification of earthquakes fromarchaeological data: methodology, criteria and limitations. In: Stiros, S.C., Jones, R.E. (eds.), Archaeoseismology, Occasional Paper No. 7 of the Fitch Laboratory, British School at Athens, 129-152.

Şenel, M., 1997. 1:100.000 ölçekli Türkiye Jeoloji Haritalar1 Antalya M10-M11 Paftas1, MTA yayinlari, No:6, Ankara, Türkiye.

Takmer, B., 2002. Lykia Orografyası, Yüksek Lisans Tezi, Akdeniz Üniversitesi Sosyal Bilimler Enstitüsü, Antalya (yayımlanmamış).

Taymaz, T., Price, S., 1992. The 1971 May 12 Burdur earthquake sequence, SW Turkey: a synthesis of seismological and geological observations, Geophys J. Int. 108(2), 589-603.

Tekinalp, V.M., 2000. Geç Antik Dönem Sonrasında ve Ortaçağ'da (M.S. 4.-14.yy) Andriake Kenti, Doktora Tezi, Hacettepe Üniversitesi Sosyal Bilimler Enstitüsü, Ankara (yayımlanmamış).

Verstraeten, G., Paulissen, E., Librecht, I., Waelkens, M., 2000. Limestone platforms around Sagalassos resulting from giant mass movements. In Sagalassos V. Report on the Survey and Excavation Campaigns of 1996 and 1997, Waelkens, M., Loots, L., (Editor), Acta Archaeologica Lovaniensia Monographiae 11/B, University Press, Leuven, 783-798.

Wells, D., Coppersmith, K., 1994. New empirical relationships among magnitude, rupture length, rupture width, rupture area and surface displacement, Bulletin of the Seismological Society of America, 84, 974-1002. 